\title{
Structure Stories
}

by

\author{
Michael Beach
}

A Thesis Submitted to the Faculty of Graduate and Postdoctoral Affairs in partial fulfillment of the requirements for the degree of

\author{
Master of Architecture \\ Carleton University \\ Ottawa, Ontario
}

(C) 2021

Michael Beach 


\section{Abstract}

The current state of world affairs conveyed in recent news media often underscores the unpredictability of what lies ahead. How might the combined effects of these daily headlines influence the world of tomorrow? This thesis will speculate on how interweaving among these narratives might suggest spatial and social futures that translate into the language of architecture.

This thesis investigation will comprise three layers: reading and analysis of current events journalism with a focus on systemic social issues, reflection about the fictional built environments of others (Architects, Authors, Filmmakers)and development of a new set of speculative architectural fictions

I hope to encourage conversations about the potential for speculative architectural fiction in increasing awareness and inspiring discussion about the futures that current pressing world issues may foretell.

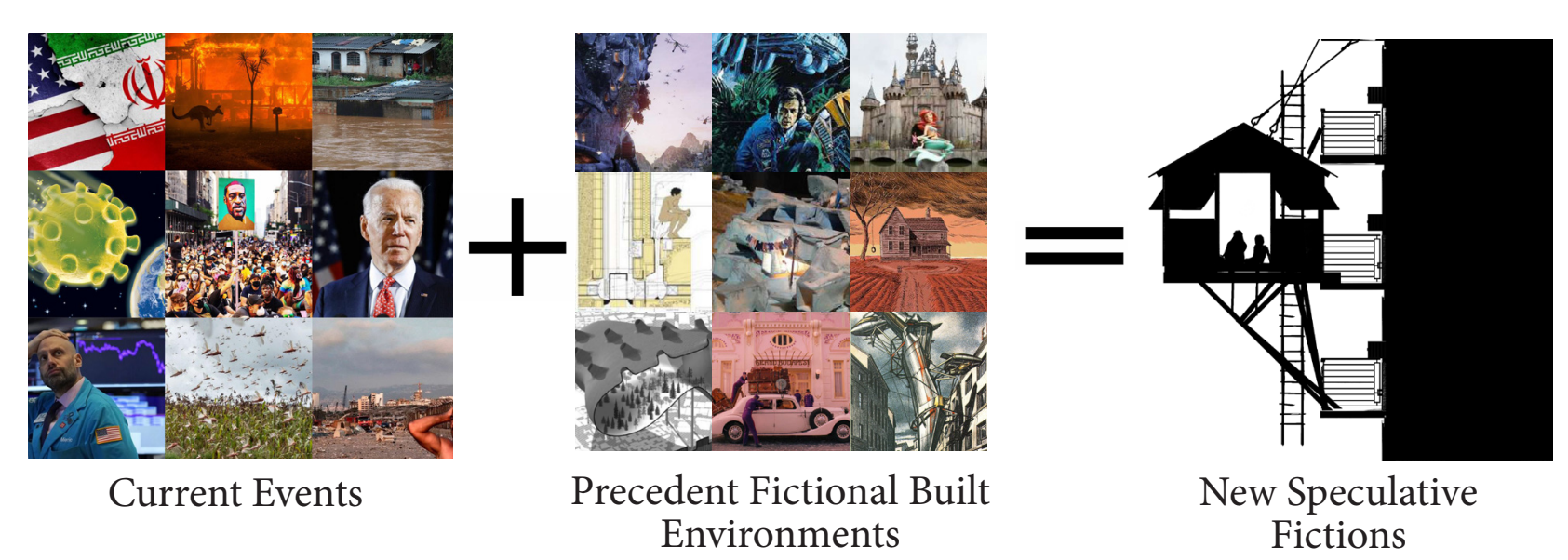




\section{Table of Contents}

02. Abstract

04. Table of Contents

05. List of Figures and Illustrations

08 Introduction

10 The Empathetic Response

14 Governing Principles for New Speculative Fictions

22 Working Methods for New Speculative Fictions

26 New Speculative Fictions

$$
\begin{array}{ll}
\text { I } & \text { Ottawa, Ontario } \\
\text { II } & \text { Chicago, Illinois } \\
\text { III } & \text { Detroit, Michigan } \\
\text { IV } & \text { Sonoran Desert, Mexico } \\
\text { V } & \text { Los Angeles, California } \\
\text { VI } & \text { Manhattan, New York }
\end{array}
$$

\begin{tabular}{|c|c|}
\hline Figure 1: & A man walks through rubble in the aftermath of a Hurricane \\
\hline Figure 2: & Black Swan (2010) \\
\hline Figure 3: & Beecher Stowe - Uncle Toms Cabin (1852) \\
\hline Figure 4: & Kerouac - On The Road (1957) \\
\hline Figure 5: & Meyer - The Day After (1982) \\
\hline Figure 6: & Miller - Babe (1995) \\
\hline Figure 7: & Obaid-Chinoy - A Girl in the River (2015) \\
\hline Figure 8: & Lebbeus Woods - War and Architecture (1993) \\
\hline Figure 9: & Archigram - Plug In City - Peter Cook (1966) \\
\hline Figure 10: & Oxygen House - Douglas Darden (1988) \\
\hline Figure 11: & Geostories - Rania Ghosn and El Hadi Jazairy (2018) \\
\hline Figure 12: & Undocumented - Ting Chak (2014) \\
\hline Figure 13: & Article - CBC News-Muriel Draaisma (2020) \\
\hline Figure 14: & Article - The Philadelphia Inquirer - Bethany Ao (2020) \\
\hline Figure 15: & Liam Young "City Everywhere” (2017) \\
\hline Figure 16: & Lebbeus Woods "Photon Kite" (1988) \\
\hline Figure 17: & Fake Polaroid - Pizza Delivery \\
\hline Figure 18: & Chicago - "High House" \\
\hline Figure 19: & Article - The Seattle Times - Geoff Baker (2020) \\
\hline Figure 20: & Article - The Financial Post- Frances Schwartzkopf \\
\hline Figure 21: & Pete Doctor “Up” (2009) \\
\hline
\end{tabular}

\section{List of Figures and Illustrations}


Detroit - "Jail Springs"

Article - Fox News - Liberty Vittert (2018)

Article - Marketwatch - Liz Seegert (2020)

Frank Darabont “The Shawshank Redemption” (1994)

Douglas Darden “Oxygen House” (1988)

Sonoran Desert - "Castle Wall"

Article - The New Yorker - Issac Chatiner (2021)

Article - Ajzazeera - Daniel Becerril (2021)

Ting Chak "Undocumented: The Architecture of Migrant Detention" (2014)

Madeline Ashby "By the Time We get to Arizona" (2014)

Sean Baker "The Florida Project" (2017)

Aaron Becker "Journey" (2013)

Los Angeles - "ICE Truck"

Article - Reuters - Anna Bahney (2019)

Article - CNN - Kate Abnett (2020)

Richard Fletcher "Soylent Green” (1973)

David Greene "The Living Pod"(1966)

Hiroshi Nagai "Untitled" (2015)

Anne Rysdale - The Tuscon Inn (1953)

David Hockney "Pool with Two Figures" (1972)

Manhattan - "Trillionaires Row"

Article - Financial Post - Emily Brumfeild (2021)

Article - NBC News - Andrew Lehren (2018)

F Scott Fitzgerald “The Great Gatsby” (1925)

Peter Weir “The Truman Show" (1997)

\section{Graphene Molecular Structure - Wikipedia} Cold Gas Thruster - MDPI Switzerland Ballistic Parachute - Flying Magazine (2015) "Diamonds In The Sky"- News Paper (Fictional) Natasha Dawn Instagram Screen Shot (Fictional)

Preliminary Sketch 1

Preliminary Sketch 2

Preliminary Sketch 3

Model Screenshot 1

Model Screenshot 2

Model Screenshot 3

Model Screenshot 4

Preliminary Rendering 1

Preliminary Rendering 2

Preliminary Rendering 3 


\section{Introduction}

"Human beings are storytelling animals. Data can persuade us,

but it takes stories to move us."'

--Susan Lefkowitz’s, McSweeney 58 - 2040 A.D

If we, as speculative Architects wish to present a speculative built and or natural environment for consideration, I suggest that there is a great benefit in presenting these environments within a fictional narrative experienced through the eyes of an empathetic character.

In recent times, increased prevalence of hurricanes and subsequent flooding and destruction of built and natural environment in the Caribbean have had tragic impacts. ${ }^{2}$ In order to bring mass awareness to this issue, rather than producing line-weighted, layered, data-scaped maps showing increasing frequency of storms and subsequent flooding over time, such as those that have been circulating within the walls of academic institutions for some time, to bring attention to this particular issue, this thesis instead would advocate for creation of a visual narrative. This narrative would be populated by an empathic character as they navigate the fractured infrastructure of Great Abaco the day after the storm searching for their family, and trying to make or find shelter. The viewer, rather than being bombarded with statistics and data, is engaged through empathy via a relatable character's reaction to the environment of study.

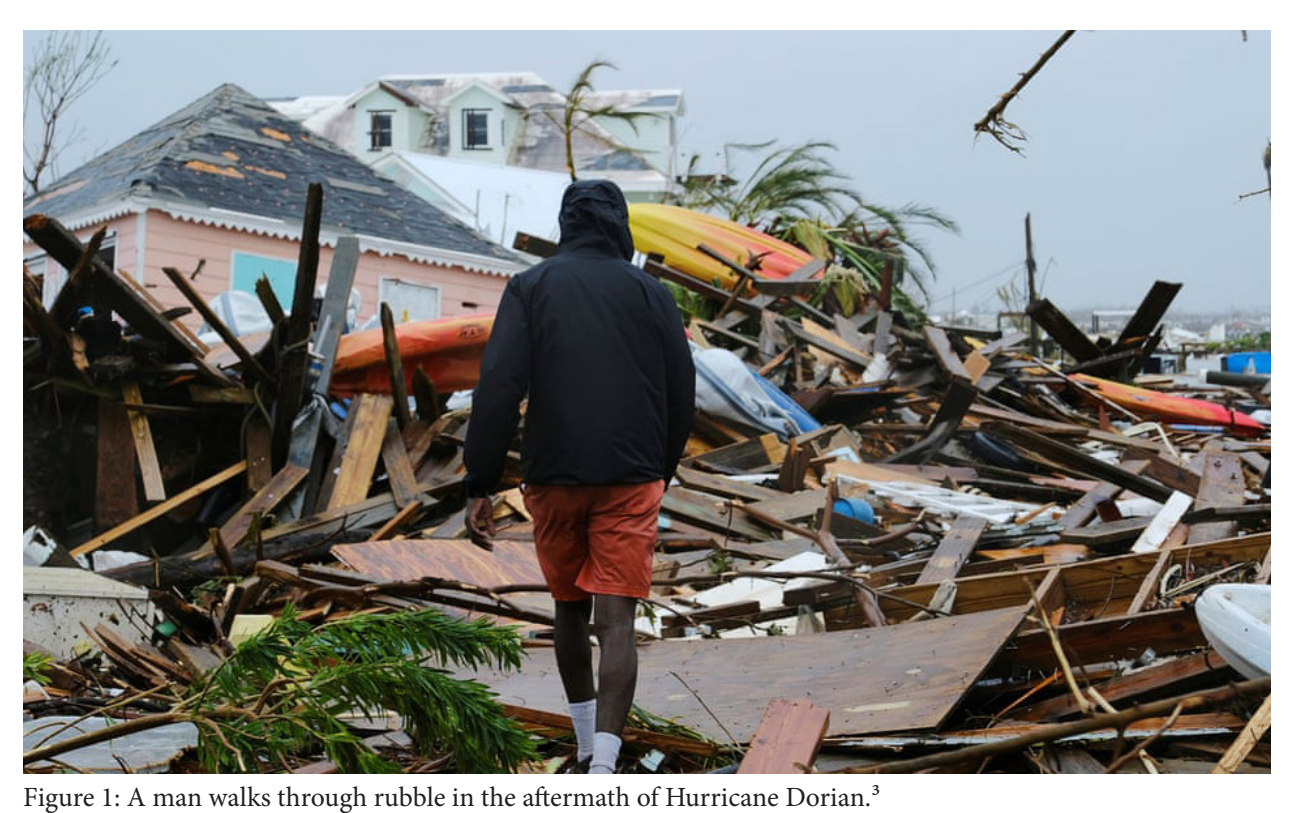

This combination of architectural specificity, situational clarity and relatable characters does not intend to offer solutions for our current urgent crises. Instead, it can hopefully provoke deeper conversations about speculative architecture's role and method in illuminating present and future challenges. In this thesis, I explore the potential for speculative architectural fiction embedded in character driven visual narrative in increasing awareness and inspiring discussion about the futures that current pressing world issues may foretell.

This thesis presents six architectural fictions, each a speculation on possible built futures that might emerge from the entanglements of current, critical events. Each is framed not just through architectural proposals, but through empathetic characters whose insights, frustrations, ingenuity, and agency bring these built environments into being, or resist the ones they are subjugated to against their will. 


\section{The Empathetic Connection}

I propose that framing an environment for consideration (natural, built, speculative, or otherwise) through its navigation and engagement by a relatable character in narrative is an effective method to engage and influence the designated viewer through an empathetic connection.

Frédérique de Vignemont, a senior researcher of the Institute of Cognitive Science, France notes: "According to a motor theory of empathy, empathy results from the automatic activation of emotion triggered by the observation of someone else's emotion. It has been found that the subjective experience of emotions and the observation of some else experiencing the same emotion activate overlapping brain areas." ${ }^{\prime}$ We are capable of engaging in this empathetic connection with fictional characters present in fictional narratives in many mediums such as film, literature, and art. ${ }^{5}$ This is quite evident, as it is common knowledge that a character's plight has the power bring its reader or audience to tears or instill a state of panic or fear.

Talma Hendler, a neuroscientist at Tel Aviv University in Israel, has monitored people's brain activity when watching films. In one particular film scene from the 2010 film Black Swan, where the protagonist hallucinates black feathers poking through her skin, Hendle notes: "The audience experiences something like schizophrenia,"' In short, the empathetic connection and emotional pairing that can occur between audience and character has a very wide breadth

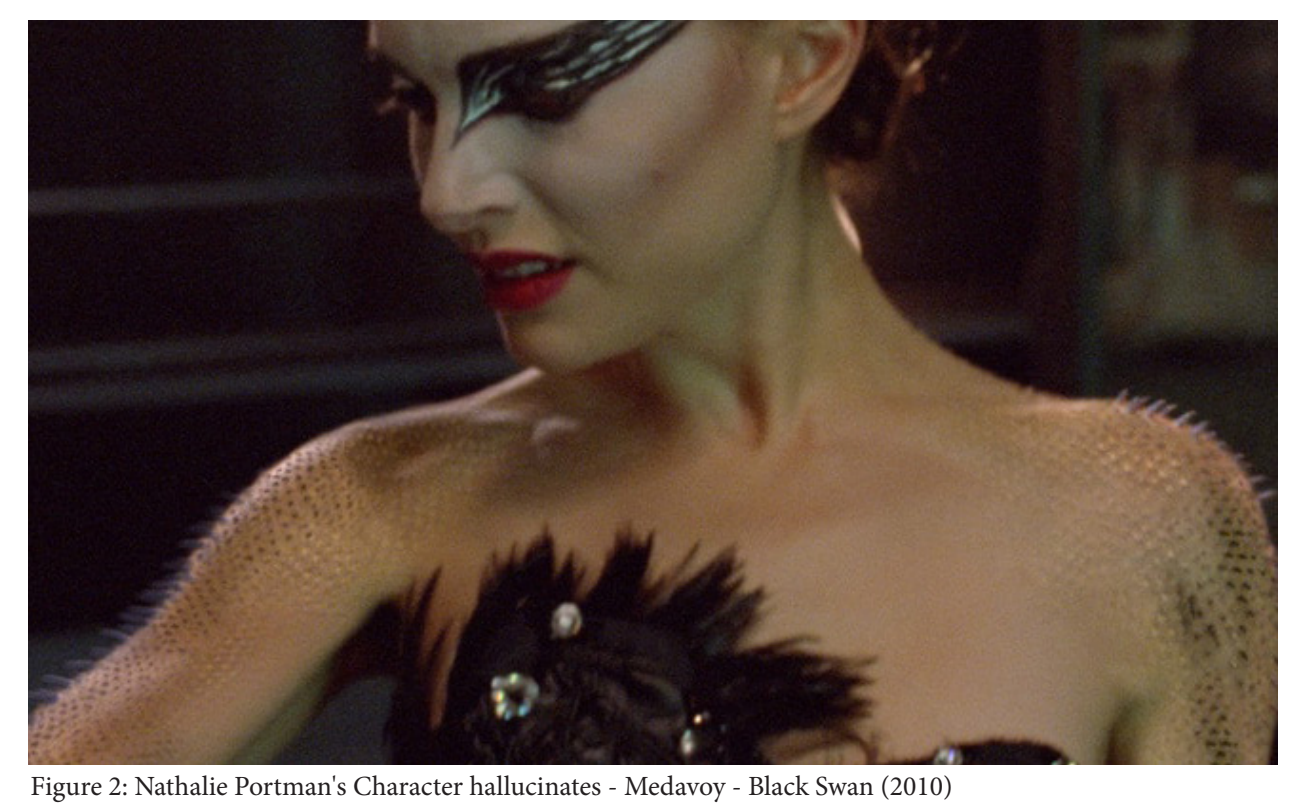

It is well studied and documented in the field of social science that when people experience empathy, they are more likely to engage in pro-social behaviors that benefit other people. Behaviors such as altruism and heroism are also connected to feeling empathy for others. ${ }^{8}$

I attest that the summary of individual empathetic responses to characters, even fictional, navigating their environment (even fictional and implausible) in narrative in multiple media forms has historically led real world mass awareness of important issues, and pushed meaningful social change. I will present a selection of anecdotal evidence below. 
Uncle Toms Cabin - 1852 (Novel) - Harriet Beecher Stowe.

This best-selling novel of the 19th century follows the struggle, attempted escape and eventual murder of the titular character, an enslaved black male. With a circulation of over 300,000 copies, the book is credited with shifting attitude towards African American slavery and assisted in laying the groundwork for the Civil War. ${ }^{9}$ Lincoln is said to have personally address the author when they met saying: "So this is the little lady that started this great war." ${ }^{10}$

\section{On the Road - 1957 (Novel) - Jack Kerouac}

This novel which follows two men on their travels across post WW2 America is credited with igniting the counterculture movement of the 1960s and influencing a generation of musician's poets and writers. ${ }^{11}$

\section{The Day After - 1982 (Film) - Nicholas Meyer}

This film, which follows a family navigating nuclear fallout in the American Midwest, had a profound impact on US President Ronald Reagan. Four years after its screening, the Intermediate-Range Nuclear Forces Treaty was signed. In his memoirs, Reagan drew a direct line from the film to this landmark agreement. ${ }^{12}$
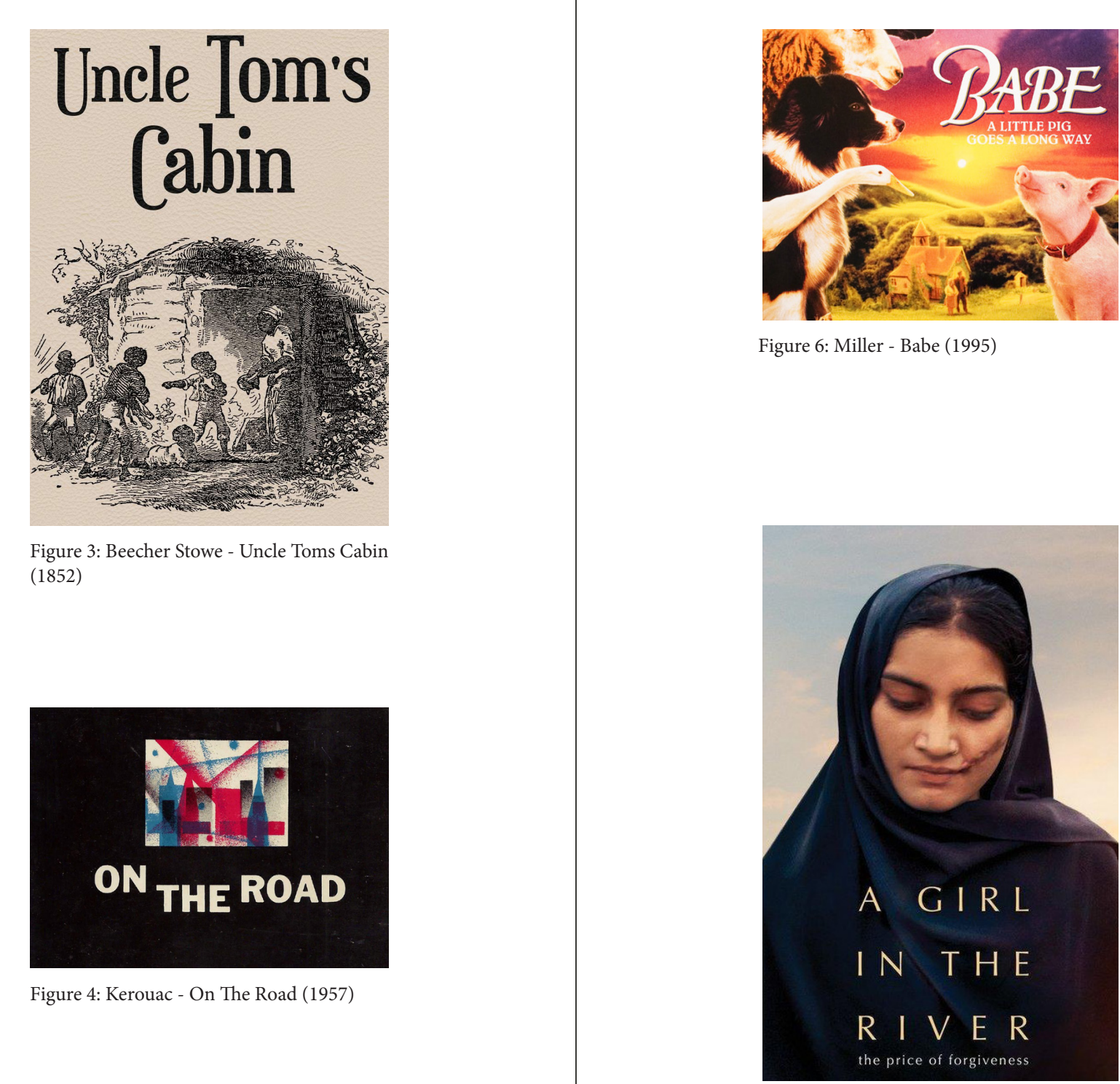

Figure 7: Obaid-Chinoy - A Girl in the River

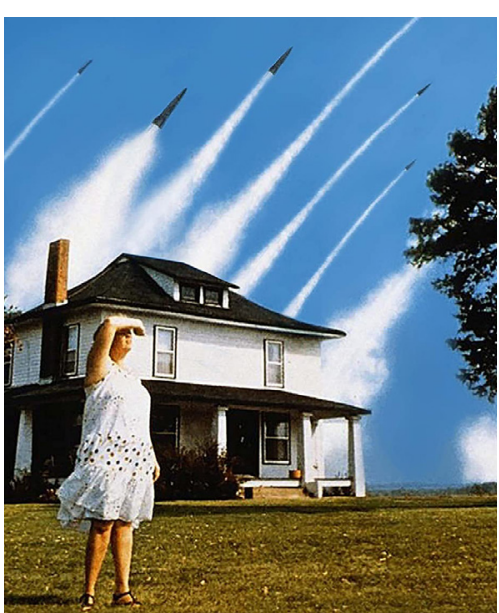

Figure 5: Meyer - The Day After (1982)
Babe - 1995 (Film) - George Miller

This film, which humanizes an anthropomorphic pig, had a marked impact on awareness of animal curtly and prevalence of vegetarianism. This is referred to as the "Babe Vegetarians" phenomenon. ${ }^{13}$

A Girl in the River -2015 (Documentary) Sharmeen Obaid-Chino

This documentary follows the recovery of a young woman shot and left for dead by her father and uncle in an "hono killing". Due to pressure from the neighborhood elders, she formally forgives them, which under rule of law, absolves her attempted murderers from prosecution. Under international pressure from the notoriety and exposure that the film obtained, and having been personally moved by the film itself, the Pakistani Prime Minister championed and passed major revisions to the country's laws on honor killings. ${ }^{14}$

As noted in the select examples above, mass disseminated works of literature and film have been linked to major cultural shifts and positive change. In all cases, its creators elected to bring awareness to a specific social ill, potential risk, or movement by engaging on a large scale with the general public through empathetic character-based narrative. I believe that we can present for consideration speculative built future environments using this viewer-character connection. I believe that empathy, not statistics are what make us care. 


\section{Governing Principles for new Fictions}

I feel it is important to produce speculative architectural work deliberately, for a clear and defensible motivation and defined goal. This section will layout and discuss the framework for the development of my work.

Inten

Clearly represented, temporal speculative architectural and natural environments can provide a tangible visualization of the otherwise abstract. As eloquently put by El Hadi Jazairy and Rania Ghosn, in their Book Geo-stories, "If such ... issues are incomprehensible in their scale, their ubiquity, and their duration, then perhaps it is through the techniques of representation that they can be made legible to the senses" ${ }^{15}$ There is an importance in providing a cohesive vision of desirable possible futures based on today's trajectory to strive for and negative ones to avoid, or if anything communicate that the future is not set and but ours to conceive and create.

When we consider speculative fiction, I believe a question we should ask is "What did the author aim to illustrate, question, study, etc. with the work?" What was the intended effect? Awareness? Drastic social change? Was it a brash political statement? A quiet protest? A warning? A message of hope? Or where they simply lacking commissions and playing around to pass the time? What is the mission statement or manifesto of the author? Who did they target as an audience, and why?

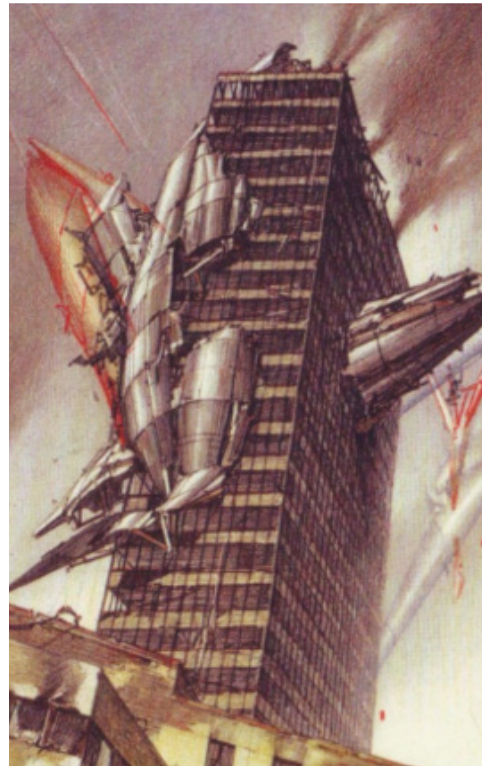

Figure 8: Lebbeus Woods - War and Archi lecture (1993)
Lebbeus Woods would famously evaluate his own work on this own blog, leaving no doubt as to his intent. As an example, his Sarajevo projects were blatant political statements against the folly of rebuilding anew after conflict without being honest about the emotional scars that cannot be erased. Instead of restoring what was lost or building anew, his speculative fictions suggested a third principle: The post-war city must create the new from the damaged old. The purpose and intended effect of Woods speculative fiction is crystal clear and stated by the author. ${ }^{16}$

As stated in the abstract, this thesis speculates on possible built future environment emerging from the entanglement of current headlines, and champions their representation through mass disseminated fictional narratives navigated by empathetic character(s). If we can, on a large scale, suspend disbelief, trigger an empathetic response, and paint a tangible visual picture of futures we want, and those we want to avoid, we may be able to inspire the redirecting our trajectory accordingly in the present.

\section{Context}

Speculative Architecture can (and I believe should) inhabit a clear and concise context. Contexts could be Political, Social, Environmental, Science Fiction, or a combination of these and others. 
The Projects of Archigram sought to speculate about how technology and mass consumerism would infect, overtake, and rearrange our lives for better or for worse. ${ }^{17}$ They were unapologetically A-Political, and A-Environmental, (operating outside todays norm of infusing sustainability). These projects were clearly grounded in the context of technology and architecture. ${ }^{18}$ The work produced in this thesis situates primarily in a social context. This is merely a personal decision upon witnessing of the gross social injustices prevalent at the time of the writing of this thesis.

Themes

Often, I find that themes are intentionally placed in the background of speculative architectural fiction, acting as almost a "subplot" to the obvious "action plot" of the work. Themes could be struggle, self reliance, agency, adaptation, agency, freedom, escape, non-interference, etc. I am interested in how these themes are interwoven into speculative architecture, their intentionality, and their effect.

Douglas Darden's final works have a somber interwoven theme: the theme of death, perhaps exemplified by the absence of figures from his illustrations. This theme has the ef-

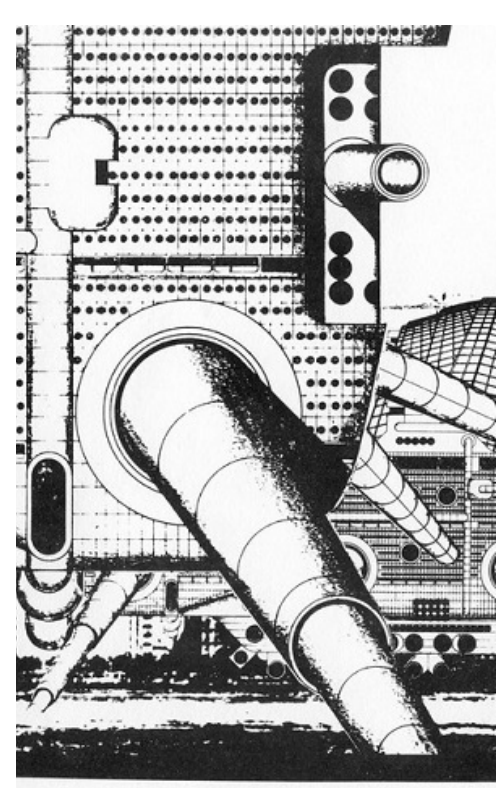
Figure 9: Archigram - Plug In City - Peter
Cook (1966)

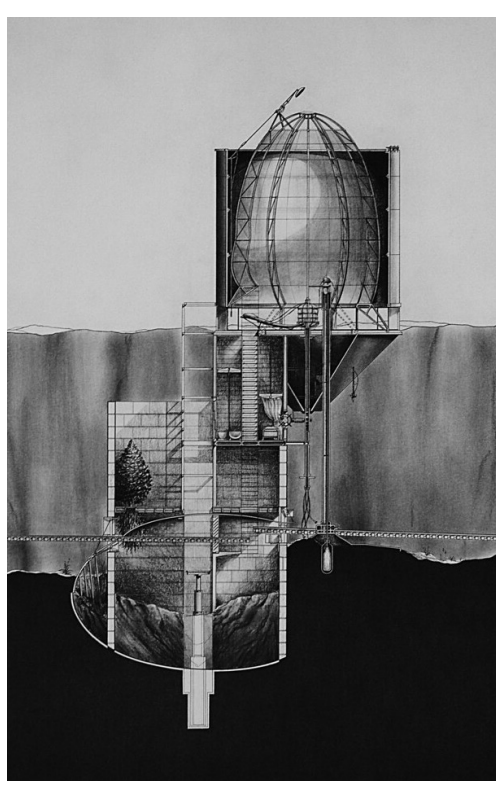
Figure 10: Oxygen House - Douglas Darden fect of engaging and connecting with the viewer through empathy. ${ }^{19}$

I feel a good story will have a clear action plot, but this plot should simply be a vessel to convey the underlying themes and social commentary. This thesis presents stories that celebrate the fundamental positive traits that all humankind share, regardless of age, race or gender such as a desire for a better life, resourcefulness, resilience, and self reliance. I feel that stories that celebrate a grassroots libertarian, constructive, non disruptive uprising against social injustices are an inspiring antithesis to the negativity, divisiveness, and viral adoption of falsehoods that embodied many events of 2020.

\section{Built Environment}

What is the specific role that the speculative unbuilt architectural representation plays in the narrative? Is the Architecture itself the protagonist / antagonist? Is it acting as metaphorical, or satirical social commentary? Is the Architecture

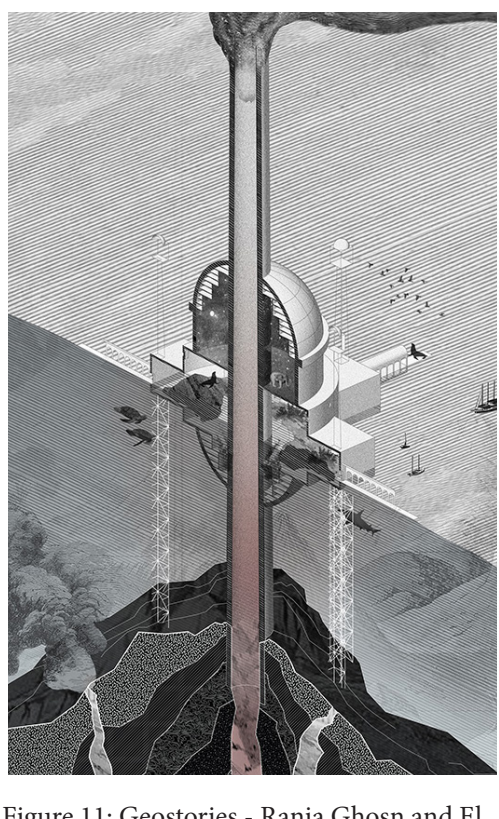
meant to resist certain dominant power structures and societal inequities or environmental destruction? Is the built environment central / inseparable from the narrative? Is it based on a speculative playing out / intertwining of curren realities? Etc

Geostories explores climate change-related issues and their impacts on the built environment. In the words of the Author, Rania Ghosn, it is a "manifesto on the environmental 
imagination that renders sensible the issues of climate change and through geographic fiction invites readers to relate to the complexity of Earth systems in their vast scales of time and space".20

All new narratives produced in this thesis not only take place within a fictional built environment but cannot exist without it. If the fictional environment is removed, there is no story. This being an architectural thesis, I believe that the use of speculative architecture must act as a fundamental plot device that works beyond merely a replaceable setting. More importantly, this thesis highlights that our built environment is implicitly tied to our socia reality. One responds to, resists, or succumbs to the other.

I explore fictional built environments that champion ground up, grassroots, conspicuous but non disruptive uprisings that use intuitive and resourceful building methods and leverage emerging technologies. This is an intentional alternate proposal to the ongoing social justice protests in the United States, where mass disruptive and destructive uprisings seek to install large scale, red tape laden social bureaucracies tasked with solving social injustices from the top down. ${ }^{21}$

\section{Role of Characters}

I believe that we understand reality in terms of the self occupying and interacting with the natural and built environment. Thus, transposition of the self onto an empathetic character engaging and navigating an environment through a narrative while suspending disbelief can be a powerful means of engaging with and considering a fictional reality.

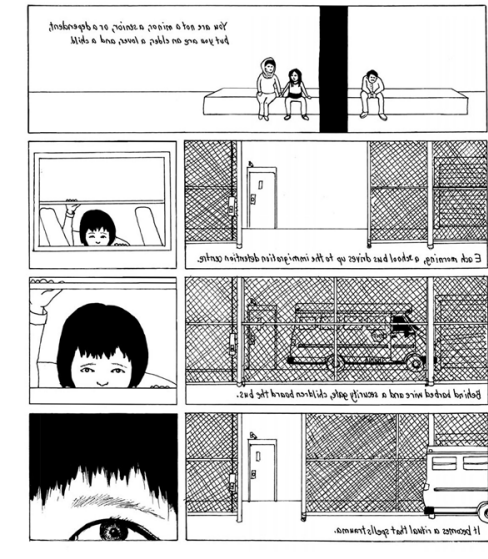

Tings Chak's 2014 graphic novel Undocumented: The Architecture of Migrant Detention uses, In her words "conventional architectural tools of representation. We situate, spatialize, and confront the silenced voices of those who are detained and the anonymous individuals who design spaces of confinement."22
Figure 12: Undocumented, the Architecture
of Migrant Detention - Ting Chak (2014)

For the new narratives developed in this thesis, characters consistently belong to a marginalized group confronting a social injustice or inequity. Empowerment over victimization is sought. I have a strong personal desire to empower groups that are often portrayed as vic tims. There are systemic social issues affecting these groups that require fundamental shifts, however what if individuals from these groups do not want to wait for a new fair and just reality that may never come?

Role of Narrative

I am a strong believer in non-written communication. If I can suggest a nearly complete temporal narrative solely with imagery, or even a single image, this to me is the ultimate success. I would like the text to ideally just reinforce what the viewer has already mostly pieced together by the imagery. This has the benefit of crossing language barriers, requiring less attention span from the viewer, and avoiding removing the ambiguity and intrigue that an image can present. 
As I began developing my narratives, I was initially very clear on what was happening, why, and on the nose about the social issue it satirized / vocalized. In the end I reduced this for a specific reason: The reader is smart enough to read between the lines. If too specific, it can come off as insulting to the readers intelligence. Also, a key technique in obtaining and holding attention through narrative is of course intrigue and mystery. People like puzzles. I will give them an image and a text that has clues in it to put together.

I believe it is ideal to have the characters voices heard. I want the story from the "butcher's mouth", unfiltered by an observer's interpretation. As such, the narratives play out in first person point of view of the main antagonist(s). Exposition and backstory is presented through written text, but also alluded to in the paired representations. A measured level of ambiguity is sought in order to add intrigue. Is it satire? Is it a serious one liner? I want the audience to decide. This two way "conversation" I feel is much more engaging, which is the name of the game. This said, the written text is minimalist. "Show it, don't say It", a mantra of film-making, is endeavored.

\section{Representation Techniques}

Over the thesis process I attempted to develop a consistent visual representation language. From the beginning, I committed to having the images be un-ambiguous in their physical composition. I want the viewer to instantly understand what the constructed space "is", and be able to move directly to contemplating its value in conjunction with the written narrative as social critique, satire, etc. Initially, I used SketchUp, Enscape and Photoshop to produce somewhat photo-realistic renderings. But I found that I had a distaste for these. I didn't like the way these images pretend to be "real". Late in the thesis process I decided to implement a consistent visual language known as planimetric composition to my main imagery. This style layers the composition in multiple of flat parallel planes (midground, foreground, background) This live theatrical style, I feel has the effect of gently reminding the viewer that they are being told a tale. This, in lieu of deception by "corporate" style renderings in perspective, I feel is more honest. This honesty may create more trust between viewer and the material presented. Further, simply put, people like being told tales, and therefore are perhaps more likely to engage and hold attention if the material is presented in this more lighthearted storytelling style. When assembling each composition, considerations for lighting, shadow, field of view, symmetry and balance was used intentionally to draw the viewers eyes to the characters, who are the focal point of each image.

\section{Platform for Dissemination and Discussion}

If a tree falls in the forest, and no one hears it, does it make a sound? Similarly, if a piece of Speculative Architecture is drawn but it dies on a University library shelf before anyone sees it, was it produced? If the goal is to incite conversation and inspire change through work, I believe that the forum in which the speculative fiction is presented and analyzed is paramount. Previously, journals and lectures were main avenues, however new forms of socia media offer new avenues to disseminate work. Can the work travel outside the walls of the "Academy" to touch a broader mainstream audience? As a response to the world we live in of arguably lowered attention spans, likes and shares, I package the fictions in an extremely easy to digest format. I.E, a single, easy to read image, and a short, easy to understand text, ideally ripe for mass dissemination through standard social media channels. 


\section{Working Methods for new Fictions}

General

With the governing principles defined in the previous section, I will detail the working methods for developing the narrative speculative fictions presented in this thesis. This admittedly developed organically via a recursive, iterative process of working between reading the news, reflecting on, and researching new inspirational precedents, sketching, incorporating technological developments, writing stories, further sketching and refining.

\section{Inspire (News)}

We are inundated with news. Doom and gloom every day. The news presents problems and assigns blame, attempts to generate outrage and seed division. But alas, the news is our eyes to the current state of the world. Once we filter out the bias, we do indeed find real people deeply impacted by social and environmental issues. The root causes of these issues is extremely complex, and thus a proposed simple solution may come off as naive. However, while accepting this, how can it hurt to ask how architecture can help move things in the right direction? News stories that illustrate individuals suffering in their built environment are evaluated to form an initial basis for the development of fictional futures.

\section{Inspire (Precedents)}

I am inspired by others work. There is possibly no real inception and everything "new" is just a mash-up of old ideas. So who inspires me? In my 41 years there have been speculative futures that I have been exposed to (largely in film) that have left indelible impacts on my beliefs and sensibilities. These are brought to the surface and examined. In the past 3 years of my masters, I have reviewed many speculative architectural fictions. These and others are also examined/re-examined and used to inspire the new speculative spaces that are developed in this thesis. These works are evaluated on multiple levels, notably: What was the author's stated intent? What context (political, social, environmental, etc.) was the work? In lieu of a detailed dive into limited presidents, I include multiple limited evaluations of works in parallel with the development of individual new fictions that they have inspired. This is a more accurate reflection of my method. I am impacted viscerally by many different sources and it would be an inaccurate reflection of my true methodology to state otherwise.

\section{Inspire (New Tech)}

I study emerging technologies and test if their probable future evolutionary state could provide useful collisions and interventions with new speculative space. I feel that interweaving applied technology into each narrative is required, as it logically will be an integral part of whatever built futures do or do not emerge. Also, bluntly, this inclusion gives something for the more technically interested reader to "snack on". Social and environmental change due to primary interest in application of cool new technology still gets us to the same destination. 


\section{Sketch}

I endeavor to "entangle" these social, environmental and technological trajectories and see what comes out. The result of this "cooking" is always represented in terms of new architectural spaces. An important consideration is to decide "who" built these spaces? Are they a result of a socialist government intervention? A grass root libertarian uprising? Do they show people being saved or saving themselves? What is the resultant message? My process for sketching involves extremely messy pencil imagineering. The messier the better. This is to avoid dismissing a silly idea because it is too difficult to draw well, (It could spark a less silly idea), and avoid falling in love with something that doesn't work because of the time it took to draw it. These drawings are not precious. Once the idea of what the space is mostly cooked, I move to the next phase.

\section{Render}

I am aware that architectural renderings (think condo brochures) can leave a bad taste in the mouth. They leave little for the viewer to extrapolate, and often fake perspective and lighting to add drama where there is none. However, considering this, the representational technique for these fictional narratives are primarily Enscape renderings of Sketchup models modified in illustrator and Photoshop using clip art and stock photography. I am more interested in discussing what these clear, legible, seemingly build-able spaces mean from a social and environmental perspective than experimenting with representational technique. Further, I believe that presenting fictions in a similar, familiar medium to cinematic spaces as represented in film or live theatre will aid with suspension of disbelief, a key requirement to engage and gain empathy from the viewer of the work.

\section{Write}

Although the fictional narrative that will allow the viewer the inhabit the new speculative space through the eyes of a character will have been brewing in tandem with the development of the previous elements, the final process is to solidify this narrative. The narratives feature a simple action plot but have subtext of specific themes running beneath its surface. Efforts are made to avoid being on the nose, maintain a measured level of ambiguity and to allow the reader to make their own conclusions, allowing a two-way dialogue, questions, and desire for discussion with other readers.

Reflect

Finally, I reflect on this based on my experiences working through the story. What works and what could be improved? What were the interpretations and feedback from others? What lessons might I take from this to apply to future speculations? 


\section{OTTAWA, ONTARIO}

Weston, Age 10

My Mom's best friend lived in the unit above us. She had a daughter, Asha. It is easy to meet girls when you are 10. Play dates are like blind dates but without the awkwardness. We both liked dinosaurs so that was it. Then Covid-19 came...

The play dates were now over zoom. But something was missing. I could see her face, hear her voice, but she really wasn't there. We tapped Morse code to each through the slab each night after her iPad broke and continued after her mom got it fixed. We both liked this The neighbors did not.

Both our moms both kept working at Mario's even after they closed our schools. The $\$ 2000$ a month couldn't cut it. They texted us every hour to make sure we were still alive. If our online teachers knew I’m sure they would have called protective services. Asha and I thought of visiting each other secretly but there were cameras. By-law was in and out daily giving fines that no one could afford.
Then, in July, The hoarder across the hall died. They were gutting it. They had left a pile of $2 \times 4 \mathrm{~s}$ and sub-flooring in the main hallway and left for the weekend. So, on one of our mother's graveyard shifts, Asha and I borrowed some wood, and built a fort and hung it off the balcony. When my mom came home and saw it, she came over, wiggled the main supports, walked back into the apartment, and collapsed in her bed.

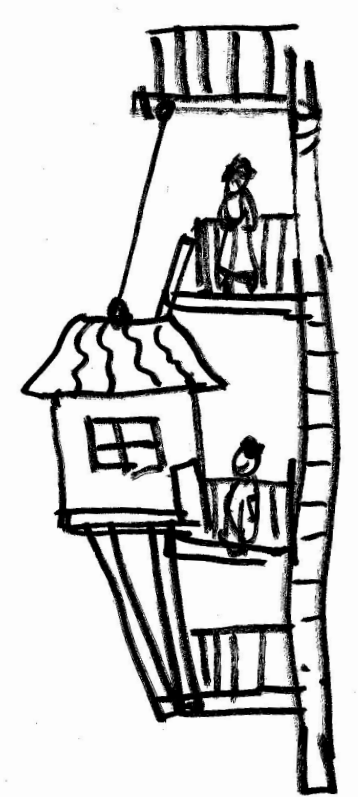




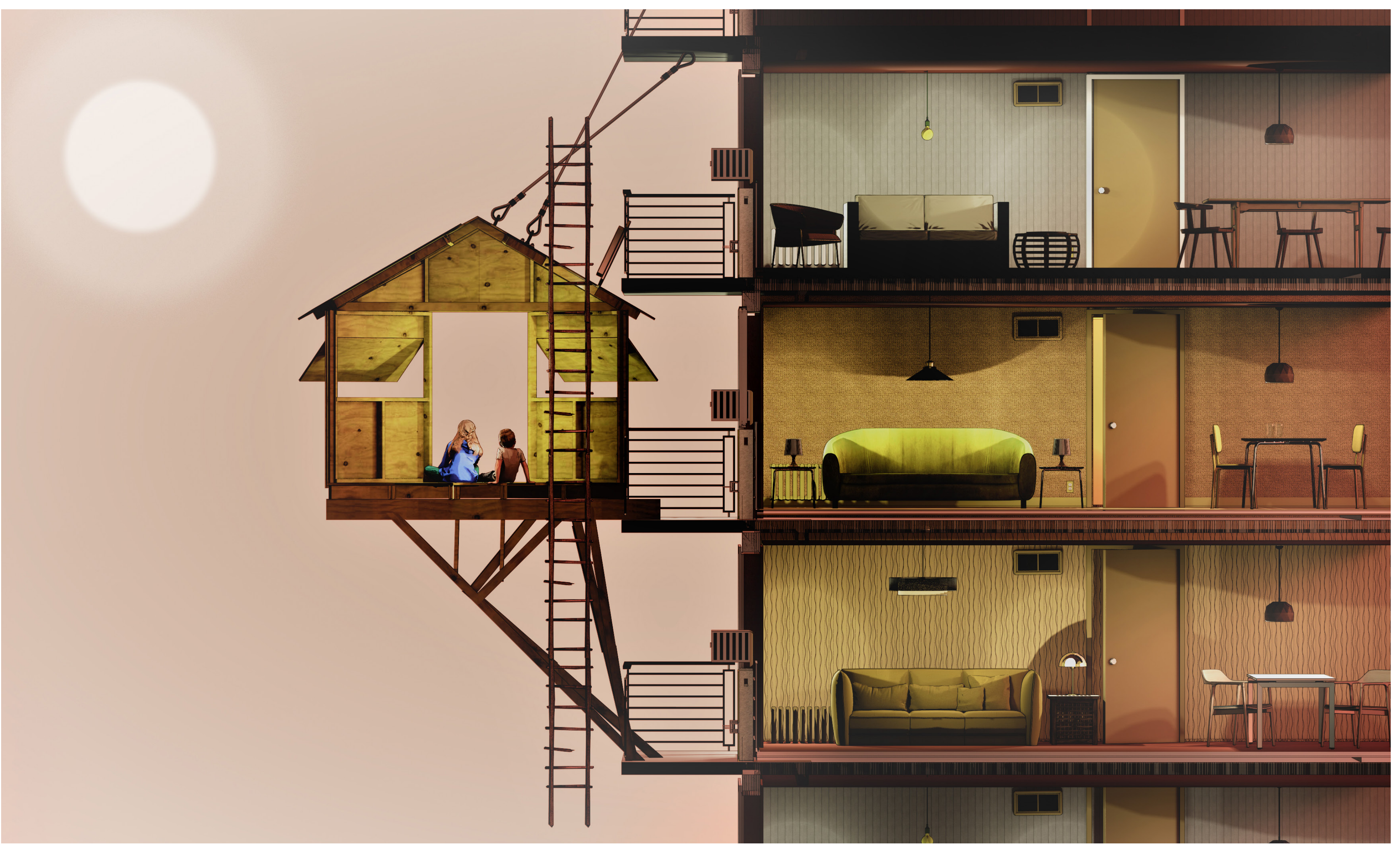




\section{CHICAGO - ILLINOIS}

Damien, Age 28

We lived at the Brentmoor Apartments for 15 years, a rather crooked brownstone walk-up. The walls were always wet. I was on first name basis with the Orkin guys. I never trusted the water. Sophie moved in, then the anchor puppy, then the twins. Our landlord, Mr. Francis finally retired to Florida and sold the building to a pension fund. The new landlord promptly gave everyone two options: "tell us how much we need to write you a check for to have you leave, or, possibly have an accident". We settled on a $\$ 1000$ payout and agreed to be gone in a month.

So, we started shopping. $0.1 \%$ mortgages, 200 -year amortizations, selling for land value only, stress tests? Money was practically free, so the price of a new house was practically infinite. We didn’t like this math. But then, we saw a house that had sat empty for a year. It was to be demolition by neglect. Finally, the city caved to the developer. When the tender went out, we bid $\$ 1000$ and got it. We cut it up and reassembled it in the middle of the street on some scaffolding, making sure the legs touched only the dividing lines.

Soon, they started calling it a "Constructive Protest", and no authority would touch it with a ten-foot pole. Works for us. We've been here 6 months. We just repainted. Garbage trucks rumble beneath us. Skipper hides under the bed. The house twists and torques; it may fall over. But that's the story of our lives. I may be the foolish man who built his house on nothing, but even sand wasn't available. Some day we may move to a place where we can lay non-metaphorical roots. But for now, this space between spaces will do just fine.

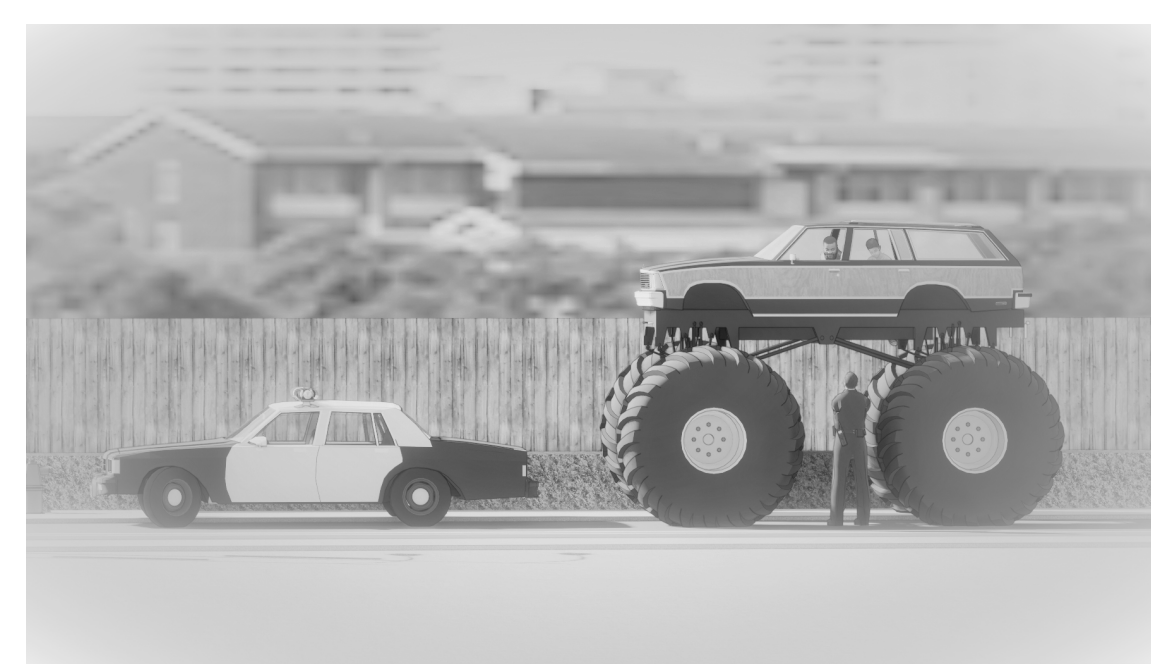




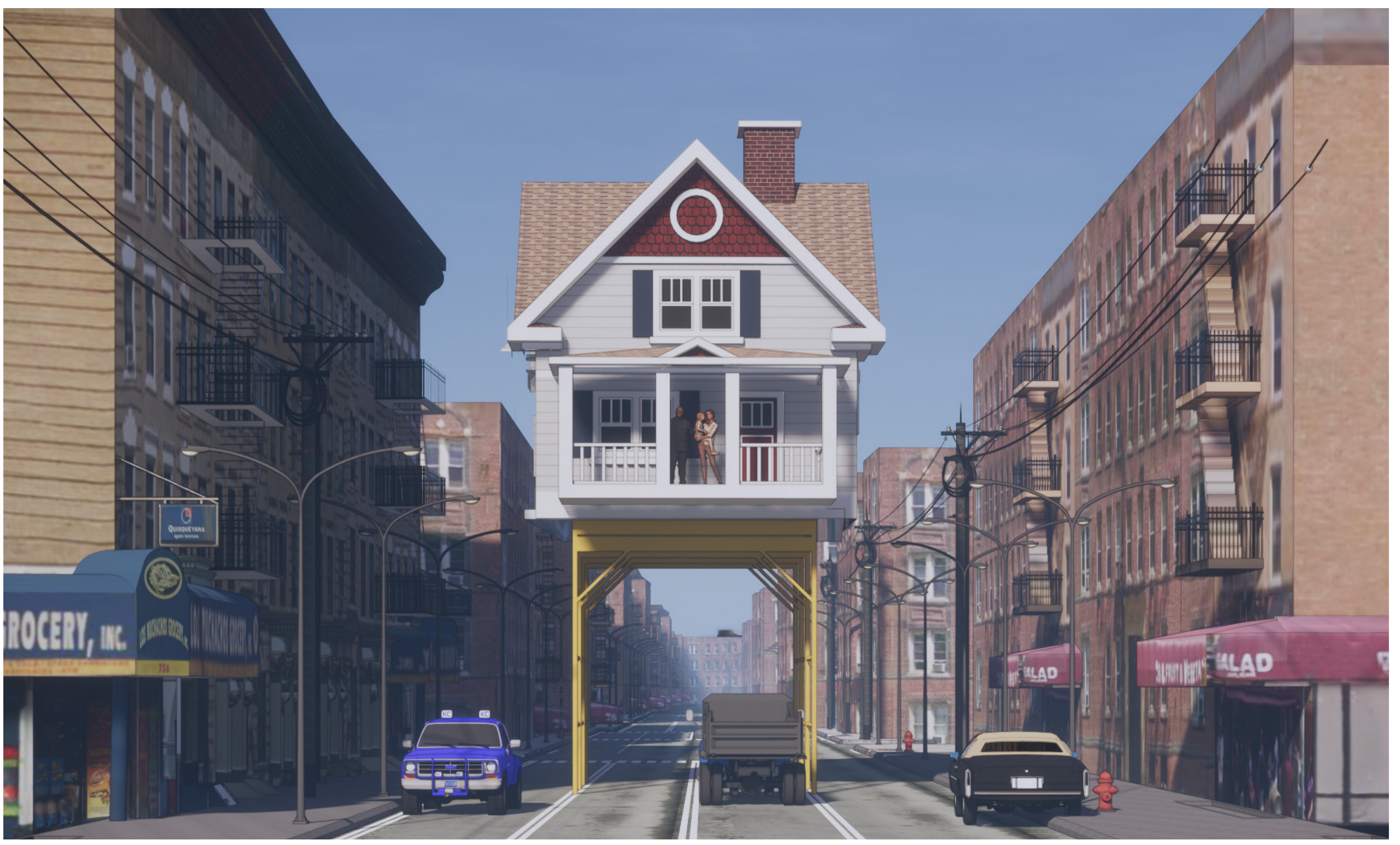




\section{DETROIT - MICHIGAN}

Lee, Age 75

We moved to Jail Springs 5 years ago. We are empty nesters. I suppose this will be our last house before they ship us off to the glue factory. I grew up here in Charlotte. My father was in and out of jail his entire life. I didn't get to know him. My mother worked herself to death trying to support us but it wasn't enough. I got into the American Penal System at 17 and was in and out until 32. I thought my goose was cooked: a convict for life.

At 35 I applied for a job at Gary's garage. He took a chance on me, taught me engines, paint and body. I worked with him until he died; then I worked with his sons until I retired five years ago, at 70 . The job kept me out of trouble. In his will, Gary left me an old hulk of a 65 Mustang, that I still have to this day.

I'm sure this is one of the reasons my wife and I moved to the Jail Springs retirement / correctional village. Ours is one of four con- nected home garages in the community. Gail is going to connect her garden next fall. I really enjoy my time with my assigned inmates. They always seem to ascend from the staircase with a smile. We spend our sessions wrenching, busting knuckles, and really just shooting the breeze about any and every topic on their minds. Some are misguided but all are good kids at heart and eager to learn. Plus, my Mustang project is moving along faster than ever before. A real win-win. 


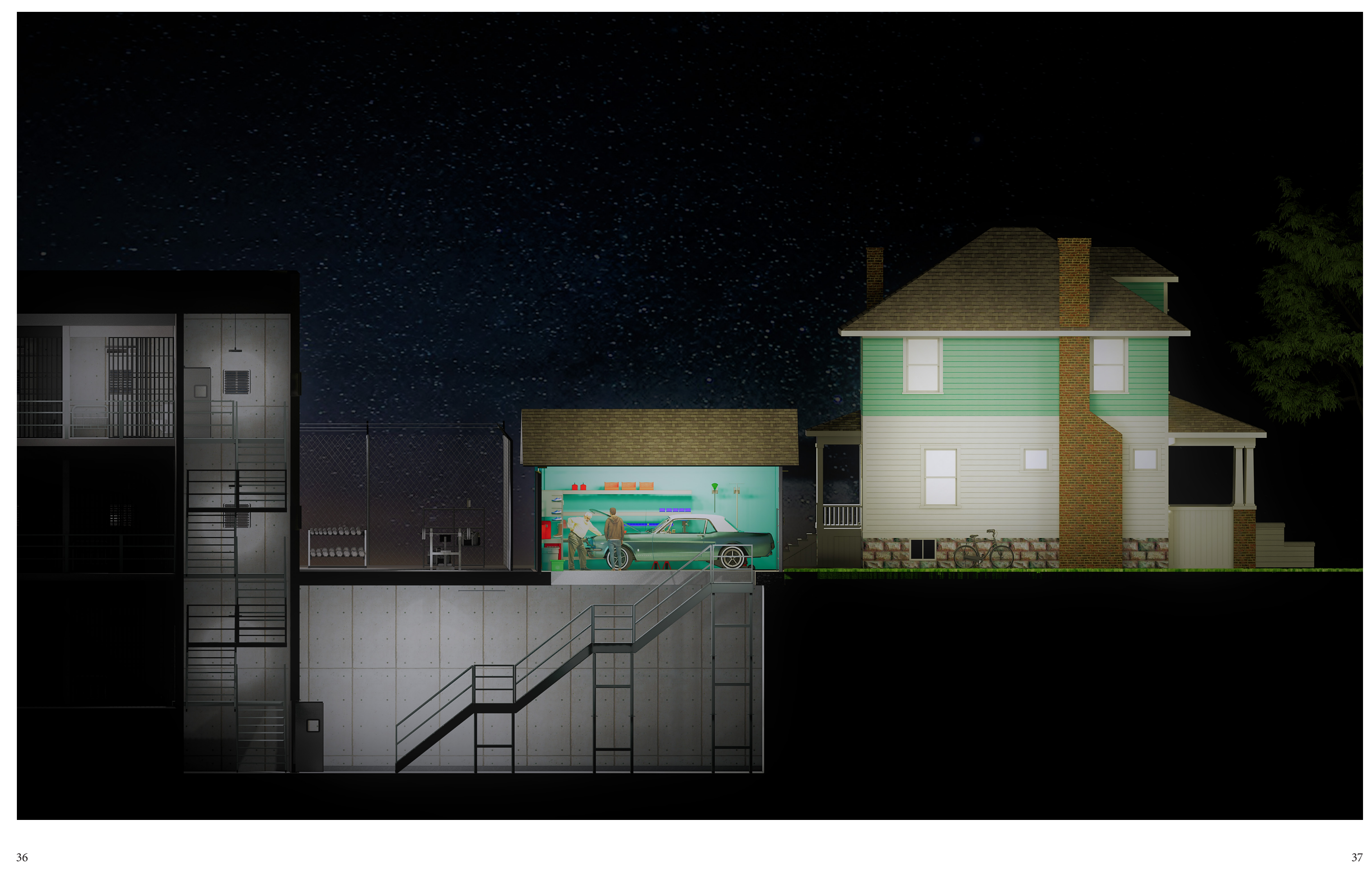




\section{SONORAN DESERT - MEXICO}

Roberto, Age 10

We have no maps. We use our shadows and my sister's watch....We weren't always alone. We met Maria and Jose in Guatemala City. They left Venezuela when their money turned to toilet paper. We were with their mother, but she took a ride and didn't come back.

But its ok, we're tough, like the diamondback rattlesnakes, the desert centipedes, bark scorpions and collared lizards. The Devil’s Highway is no match for us. We make a fox hole to hide from the coyotes. Put a garbage bag over it and it sucks the water right from the air. But this time, not enough. No problem, we are almost there, the next ridge. Or if not, the one after that.

We press on. But now our eyes are red. We have no sweat left in us and I'm having trouble thinking. Its okay, lets lie down for a minute. But then, a gust of cool air. It gave us strength. Get up. Over one last ridge, and it was there

The Beautiful Wall. It stretched over the horizon in both directions. The cool breeze of the snow-covered, American mountain range, the highest on earth, flooded over the wall into the scorching Mexican desert. The draw bridge descended; the trumpets burst. Our new parents welcomed us into their arms. 


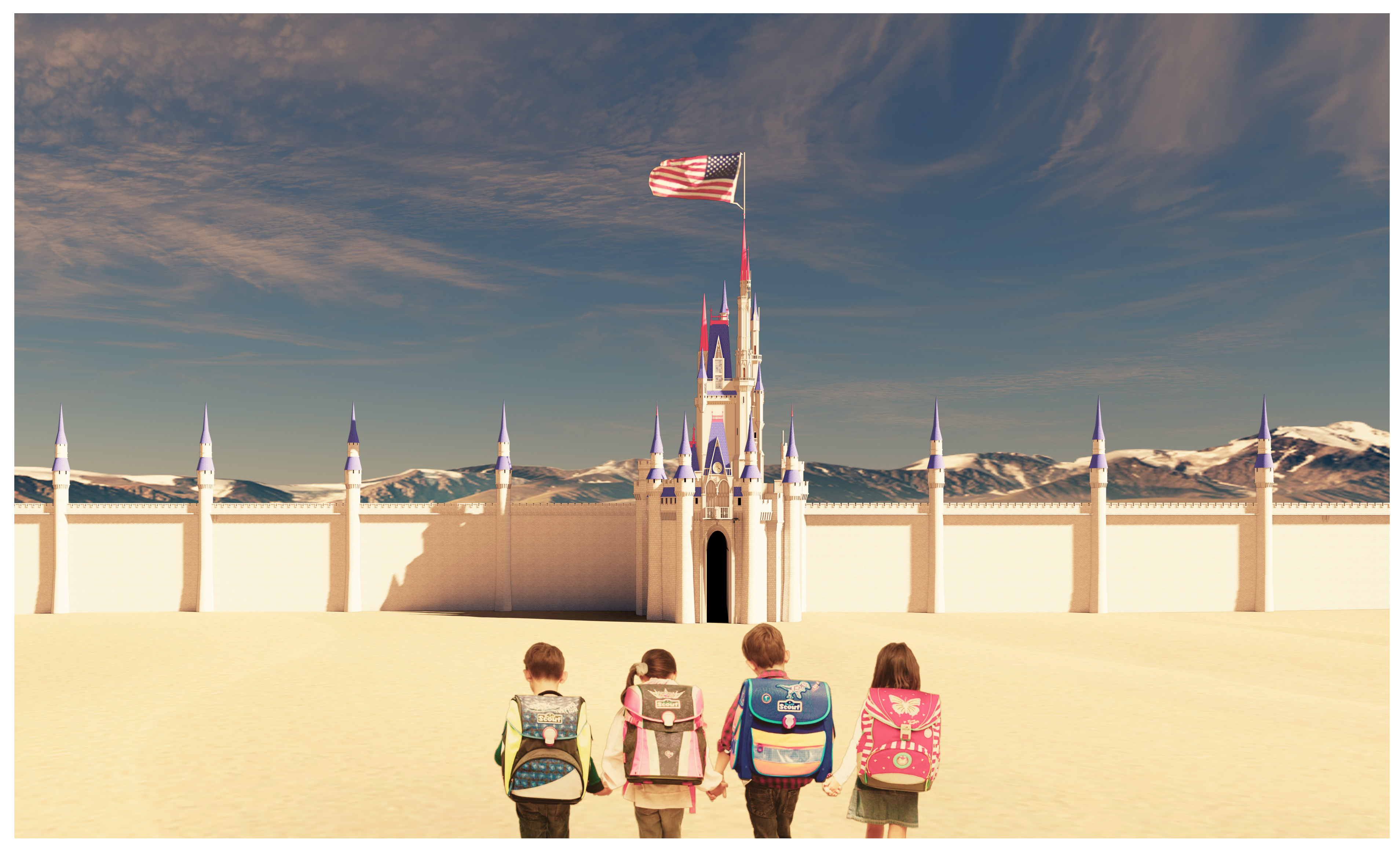




\section{LOS ANGELES - CALIFORNIA}

Bart, Age 24

My partner Giselle and I had been each renting a pod for severa years in a 4 Unit Chevrolet Caprice convert in Van Nuys. The place was awful, poorly ventilated, the location sucked. But it was all we could afford that offered mechanical cooling, even on our $\$ 350 \mathrm{k}$ a year combined earnings as Non-Fungible Token miners.

2038 was a record year for deaths from environmental heat exposure in L.A county with over 4,000 fatalities. With average yearly tem peratures at over 120 degrees, a broken air conditioner was lethal. In response to the surge in deaths, the county announced plans to upgrade and expand its aging morgue refrigeration systems and dispose of the older units on government auction sites. So... Giselle and I, along with a couple of our pod mates crowd funded the purchas of several $17^{\prime} \times 3^{\prime}$ body fridges, and found a deal on an older Tesla Semi. Some serious elbow grease later, the ICE Truck was born.
It's turned out great. We spend 3 1-hour sessions a day in a coffin. Each time our core temperature gets ratcheted back down, and then we go out again into the sweltering heat. A temperature yoyo, but we are surviving. And now, we are in business, renting the coffins out for 2 Satoshi a minute. Soon, we will install letting devices in the units, so people can also pay their rent with blood and or plasm

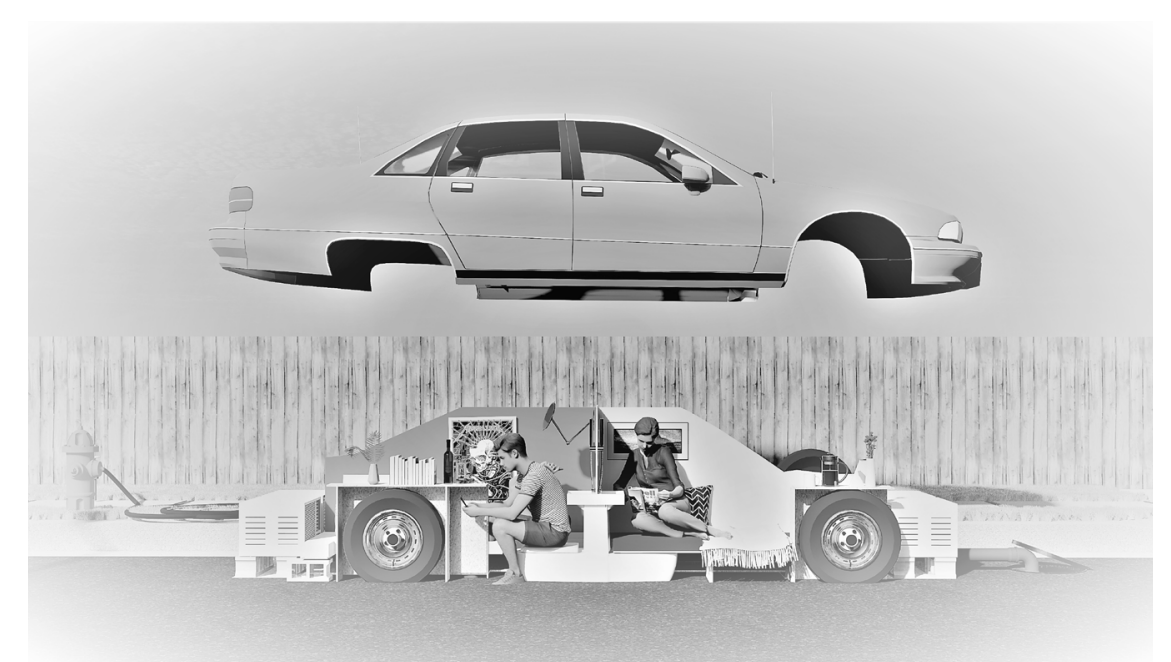




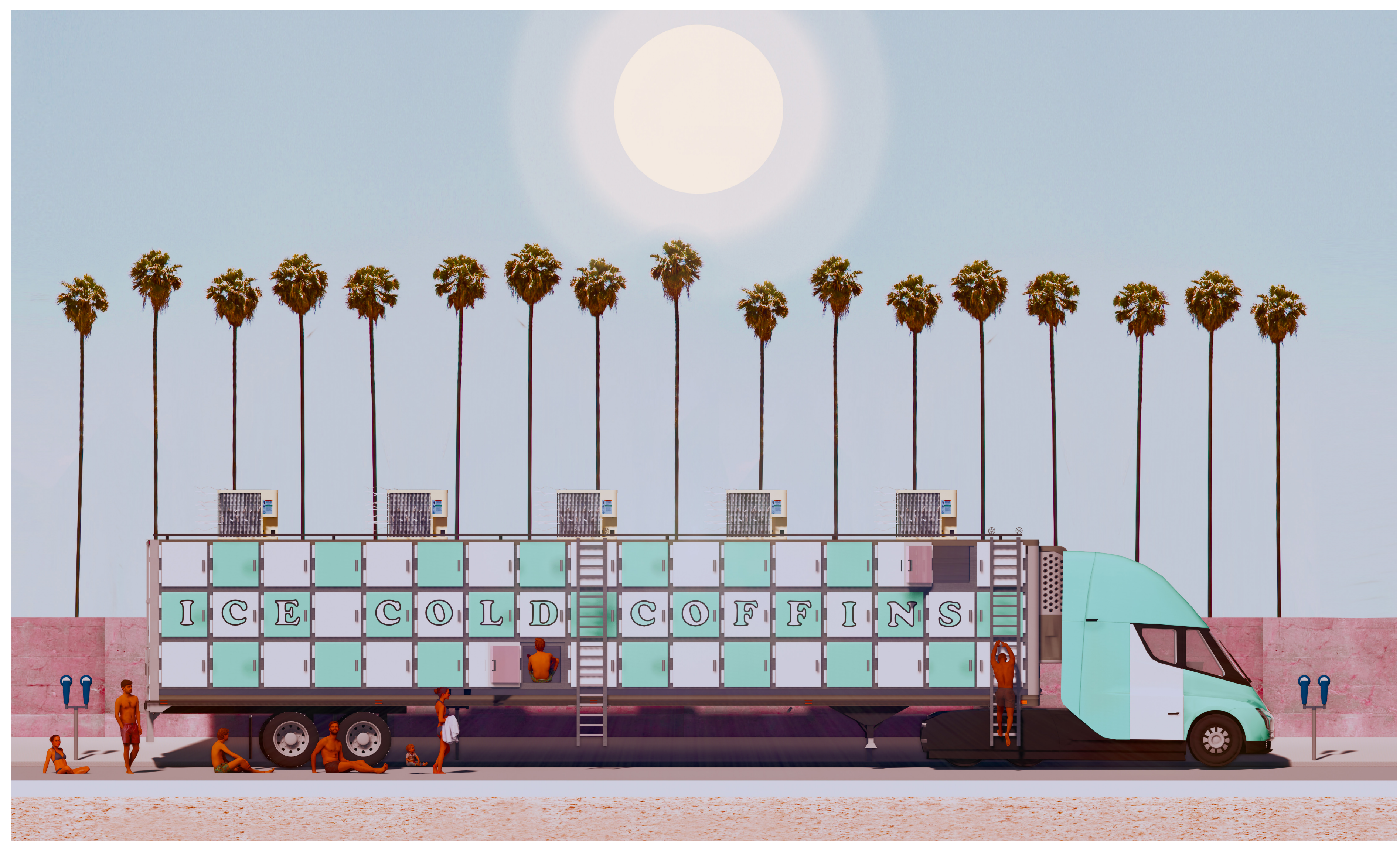




\section{MANHATTAN, NEW YORK}

Natasha, Age 35

He calls it his love letter to New York and the Art Nouveau, of which he has several examples. Also, as an Engineer in his previous life, he wanted to show what was possible with static cold thruster blip stabilizers and graphene molecular structure. No one has achieved this slenderness ratio before.

The deal rescued the city. It will keep Manhattan on life support for at least the next century until renewal. He tells me, that every day, as soon as he gets out of his drone, he can forget the world. He has created his own. Thanks to his friends at General Dynamics, we are secured. Get within the perimeter, you'll wish you hadn't.

So, diamonds light up the sky in Manhattan, but they belong to no place. With my smuggled ocular implants, I've seen a thousand sunsets set over the horizon, through the virtual façade, over Trillionaires' row. In our forest it never rains, it just sprinkles. The seasons change but the snow is always the same. It's time for us to go.

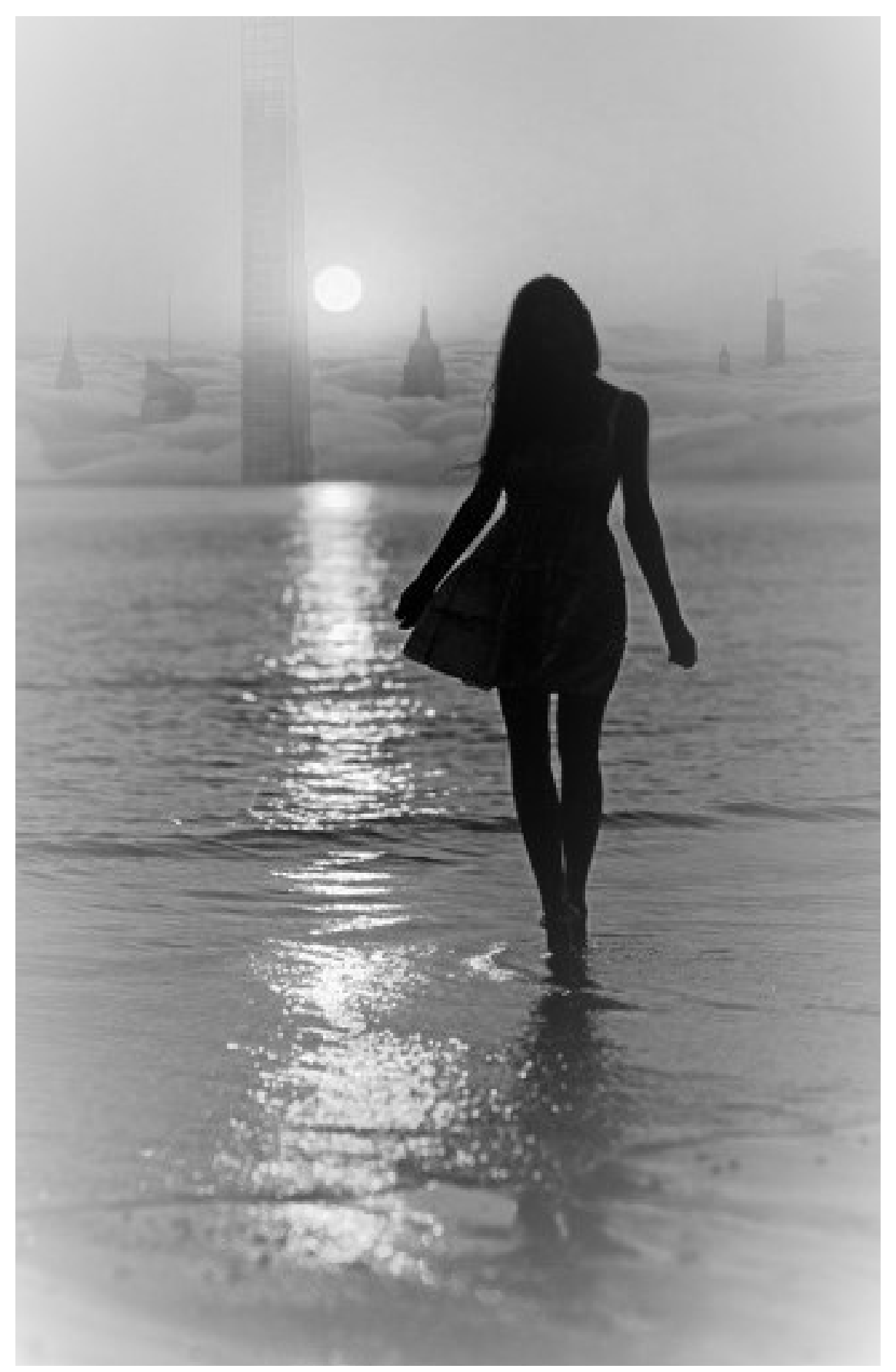


Through the cave, into the control room, stepping out onto the Surface to Air Missile Platform, released from the active dampers, the sway was sickening but real. The graphene spokes creek beneath us as they tensioned and released. I leaped, holding Brandon, and my calculations were correct. The plume opened. The updraft slowed our decent. We hit our target right across from the Tavern on the Green.

Over the past 3 years, the shelters got my hand made blankets but more importantly I got my hand made parachute from the woo waste that went unnoticed.

With our American refugee status confirmed upon touchdown the recovery drones retracted and recoiled, defeated. A new opening was posted and filled within seconds. Natasha, although another Natasha returned to the Sapphire within minutes.

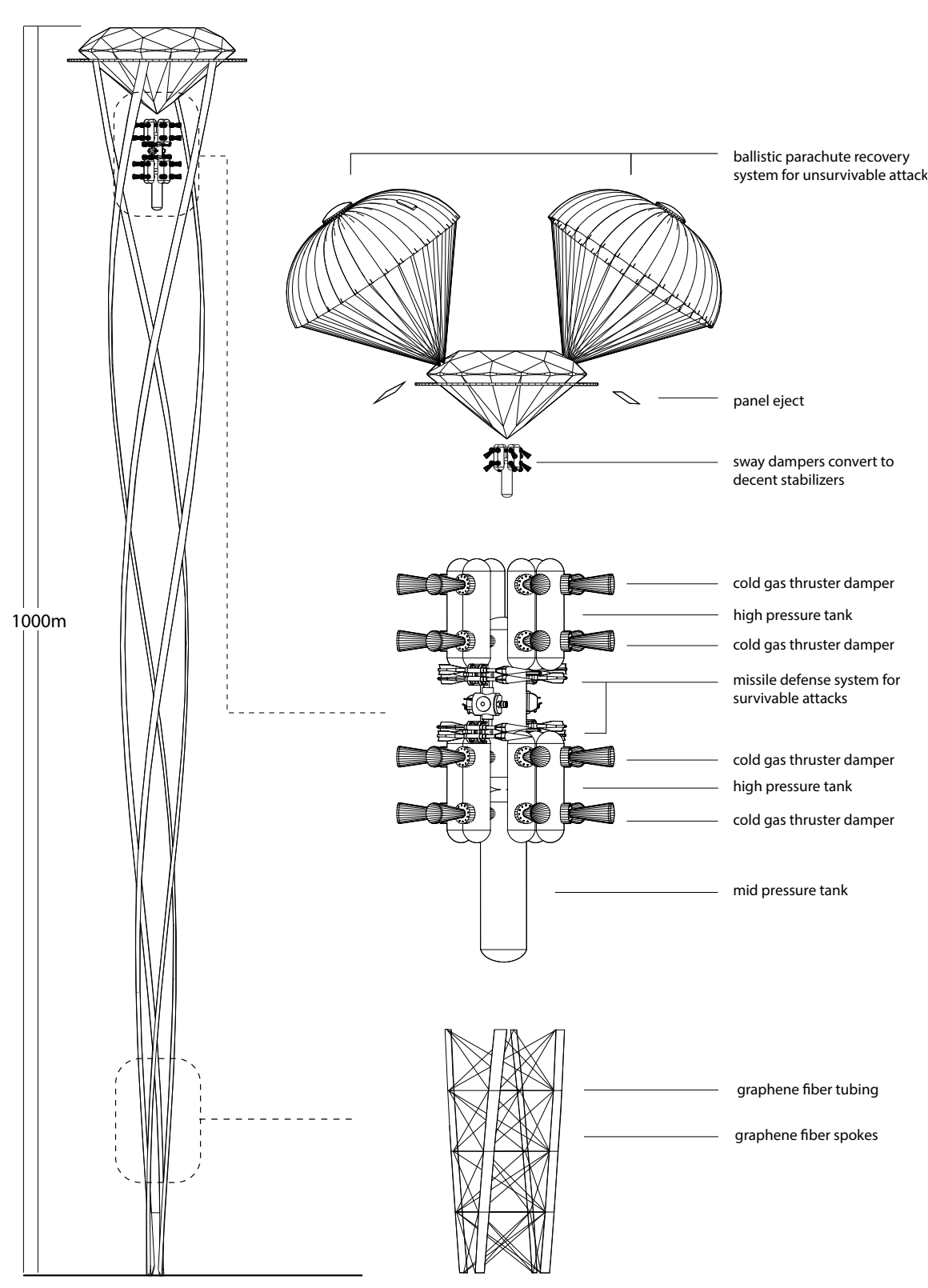




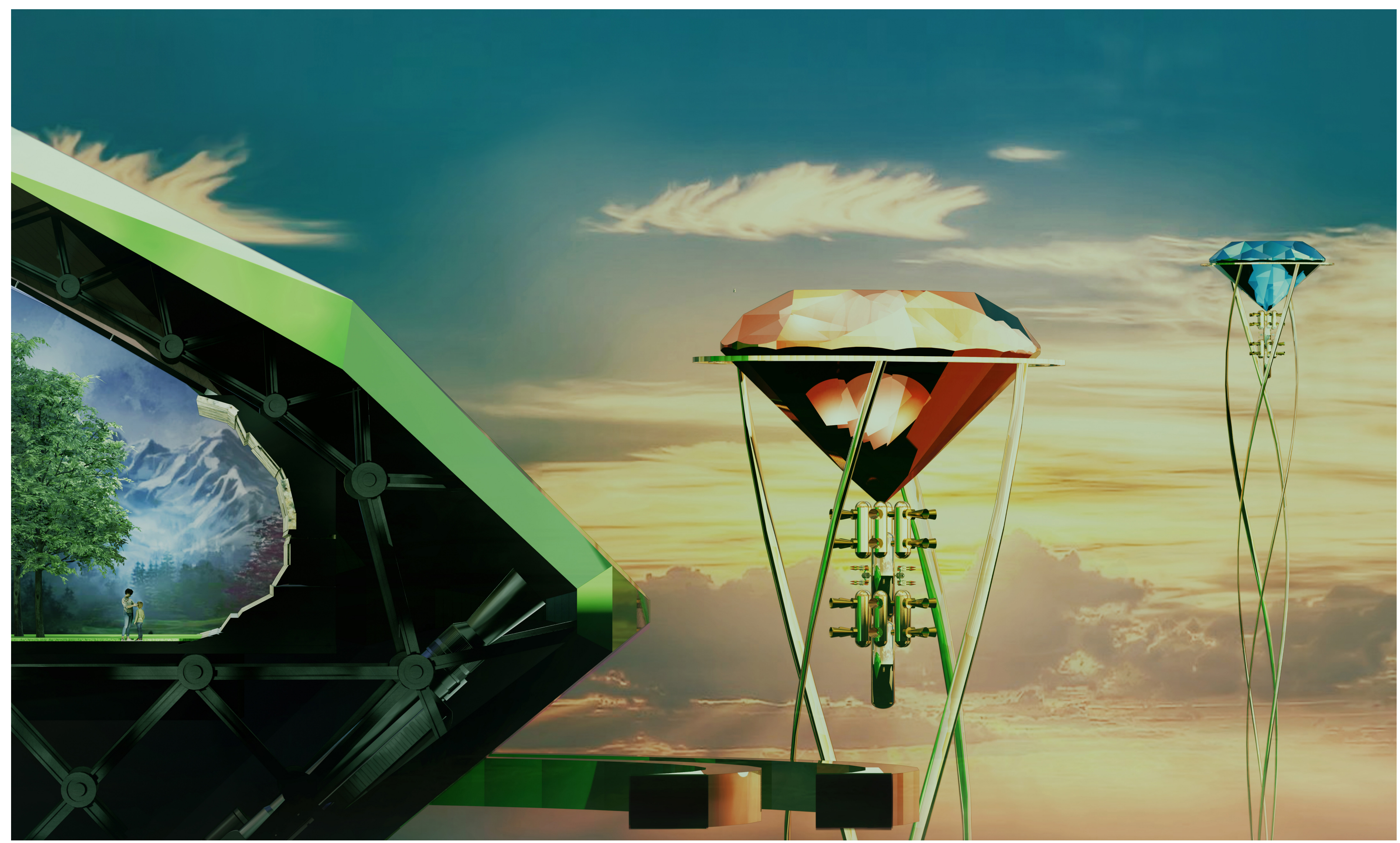




\section{Behind the Scenes}

\section{OTTAWA ONTARIO}

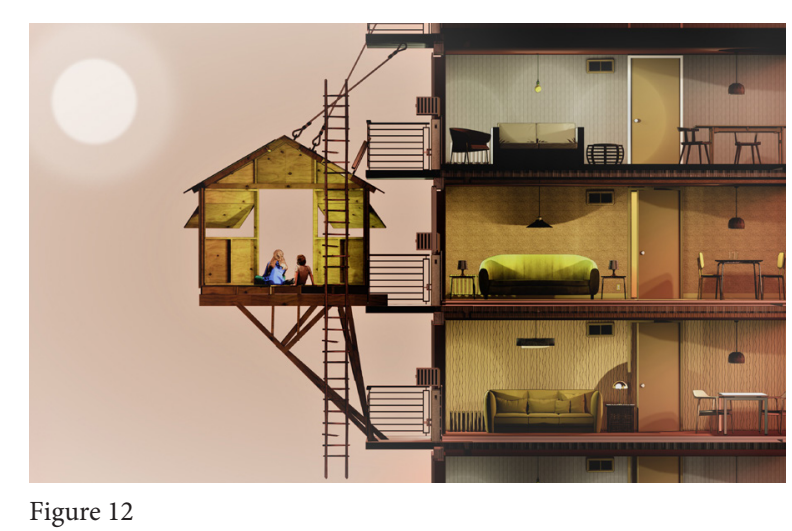

4⿳⺈⿴囗十⺝刂 CBC

News

The inspiration for this first story is of course the Covid 19 pandemic and the toll of quarantine. Multiple news articles document the impact of the pandemic on children in particular. ${ }^{23}$ As quarantine is a highly intimate interaction with the built environment, I felt there was an opportunity to experiment with a speculative architectural response.

Inspiration

I am inspired by the work of Liam Young. Young's City Everywhere envisions a faceless dystopian megalopolis. Effectively this project is the ultimate expression of communal isolation. I wondered, what are the human stories that take place within? Lebbeus Woods' Freespaces confronted the boring, reMuriel D

Bethany Ao - April 29th 2020

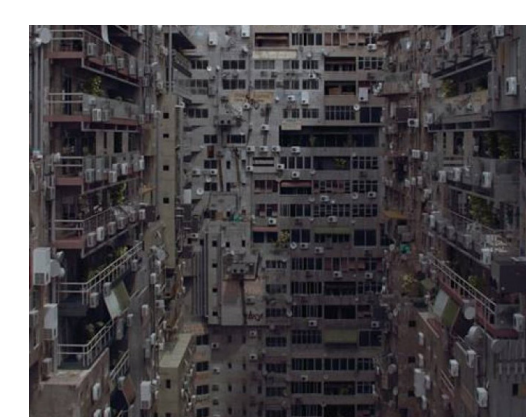

Liam Young (2017) Youngs' "City Everywhere" envisions a faceless dystopian megalopolis - Effectively the uls
mate expression of "communal isolation" Figure 15

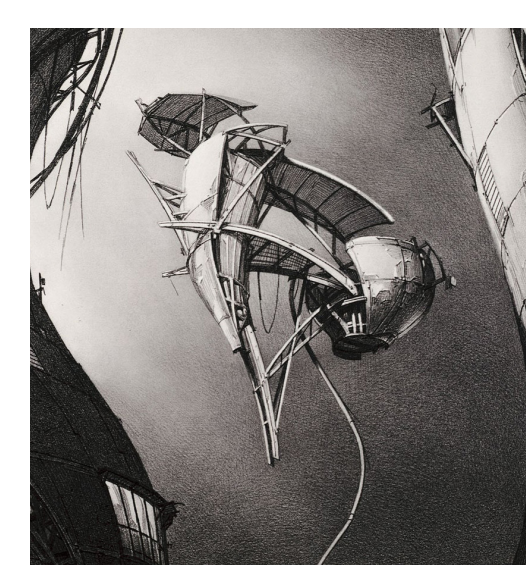

Lebbeus Woods (1988) Woods' "Photon Kite" confronted the boring repetitive spaces humans have become accus tomed to living in by challenging the "Omit Figure 16

during COVID-19 malnutritio

\section{The Philadelphia Inquirer}

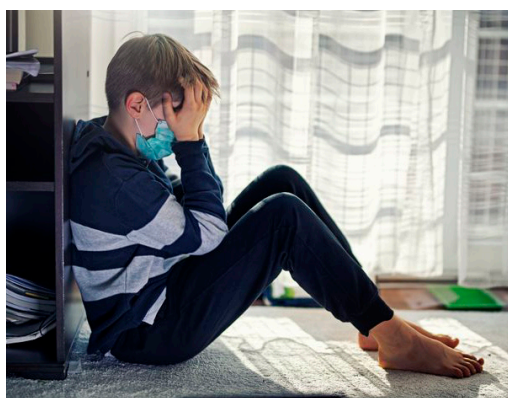

One in Five Children showed DeOne in Five Children showed De-
pressive Symptoms after QuaranPolaroid - Pizza Delivery

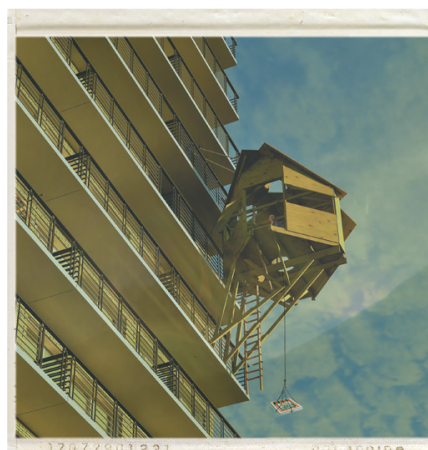

petitive spaces humans have become accustomed to living in by challenging the "Omnipresence of the Cartesian grid ." Some seem like scabs, growths, or even parasitic infections on buildings. They broke the monotony and created their own little ambiguous heterotopias.

Intent

The experience of isolation, loneliness and depression is perhaps the most fundamentally shared, cross-cultural human experience of 2020. For children, autonomy is limited simply by their stature and lack of freedom and resources, and the pandemic has exacerbated this. However, there are advantages to being a child. A child effectively is immune to the rule of law. Further, I have found that the younger one is, the more pragmatic they are at problem solving. You are scared? You make a fort and hide. I remember doing this as a child simply by re-arranging the living room furniture. In reflection, perhaps it was to create a semi autonomous kid zone. As the scale wouldn't allow adults in, you had created your own hetero-topic space. I wondered how children could break free from the despair of their pandemic induced confinement through architecture. Further, I wished to propose An alternate form of representation - The fake
Polaroid. I decided instead to go with plani-
metric composition for the final rendering. metric co 1
Figure 17

a subversive alternate method to protest lock-downs without putting others at risk. 


\section{Context /Themes}

This work takes place within our global social context. It is apolitical and hopefully representative of a quintessential aspect of the human condition. I wished to have multiple themes underlaid within the narrative and imagery: Breaking free, self reliance, determination. The need for freedom, autonomy, agency, and companionship.

\section{Built Environment}

The intervention is meant to celebrate the beginning of the bottom-up approach to constructive problem solving that will be pervasive in this thesis. Our protagonists labour to better their situation by building their way out of it themselves. So, what would a kid build? I think they would just go the ultra pragmatic route, using whatever they could get their hands on. So, the tree house vernacular seemed to fit. As noted, the "tree house" takes the stance of a quiet personalized rebellion against the authoritarian, one size fits all almos communist era housing block the children live in.

\section{Characters /Narrative}

These characters, as children, have not yet been indoctrinated with victimhood mentality They don't have a concept of the impossibilities and restriction due to regulation and red tape. They react pragmatically, just as kids all around the world do when they built forts. The narrative follows the children as they are left isolated, eventually break free and reunite. It is a simple age-old archetypal story meant to relatable and inspiring.

\section{Representation}

The principle final rendering was the first produced or this thesis using planimetric composition. The characters are intentionally placed as the compositional focal point. This reinforces that the space should be read/experience through the eyes of the character. Section, a quintessential architectural representation shows the precarious dangling of the new ephemeral construction. This was the first rendering in which I settled on the challenge of telling each narrative with a single image. The image gives hints of backstory. The empty apartments (were they abandoned?) The open hatch, the intervention contrasted with the soulless inhumane multiplicity of the prison like units that are being escaped all attempt to reinforce the thematic goals of the narrative.

\section{Final Reflections}

I believe that what brings people together is finding common humanity. I hope this was successfully communicated in this narrative and work of speculative architecture. I feel it works as an prelude for the subsequent narratives as it takes place in the present, is about a very simple, close to home challenge thus has the highest likelihood of triggering empathy, which can set the viewer up for the subsequent fictions. It hopefully helps us channel the rambunctious child in all of us, inspiring individual conspicuous but peaceful acts of revolt against oppression through architecture. 


\section{CHICAGO}

ILLINOIS

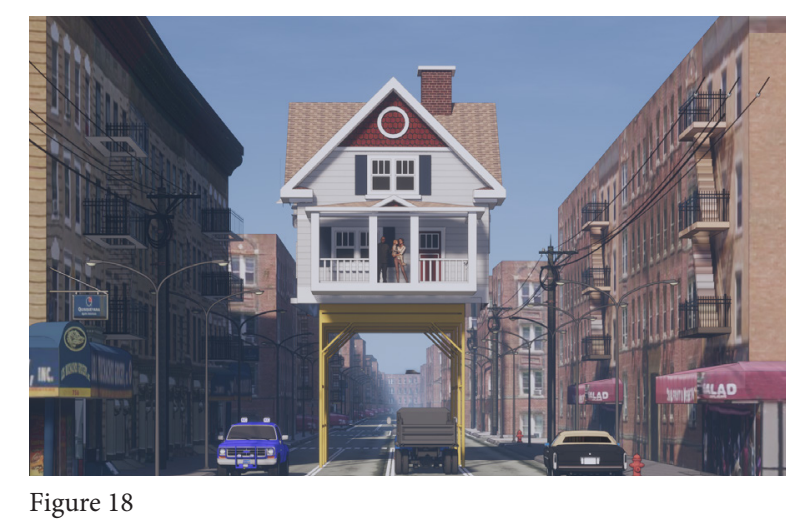

\section{The Seattle Times}

News

This work is inspired by the ongoing affordable housing crisis and social justice movements and protests in the United States. The pandemic has exacerbated the affordable housing stock in North America, with housing starts disrupted by supply chain issues and economic uncertainty. ${ }^{25}$ In the wake of the George Floyd murder, The Chaz / Chop protesters in Seattle occupied their Capital Hill, and demanded redirecting of police funding to community programs. The protesters overtook private property and vandalized and destroyed local businesses. ${ }^{26}$ In response, President Trump decried the occupation as a sign of "totalitarian takeover" that will lead to "fascist outcomes" and could "metastasize across the country." Saying the Washington state government "has handed over an entire portion of the city to domestic terrorists."27 This drastic spin doctoring and weaponizing of the event to enrage his right-wing base possibly overshadowed

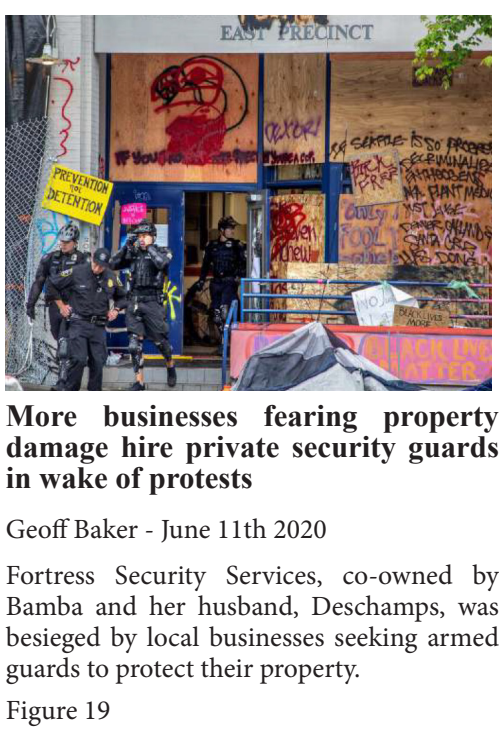

\section{FINANCIAL POST}

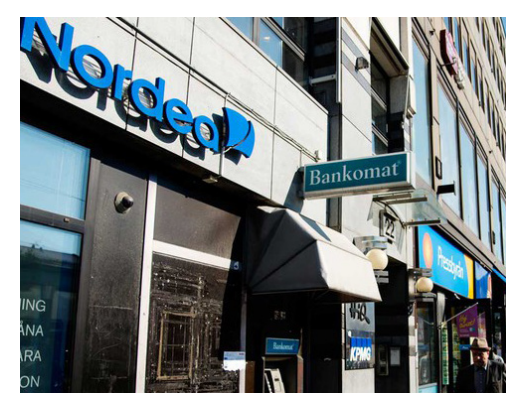
u can now get a 20-yerr for two decades without paying interest
comes as central bankers across the globe Figure 20 The once unthinkable notion of borrowing

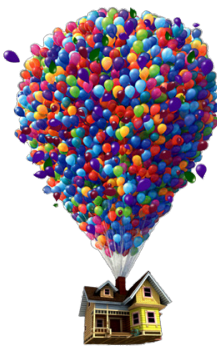

Pete Docter (2009) Docters film " $" Y p^{\prime}$ involved a "nail house" protest. As we all remember, the protagonis
eventually attached balloons to the house

Figure 21

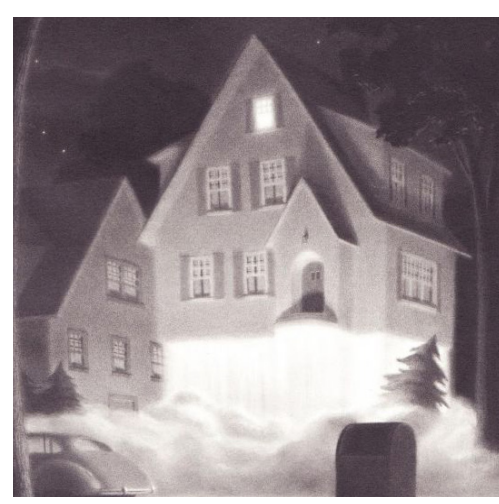

Chris Van Allsburg (1984) Van-Allsburg's "The Mysteries of Harris Burdick" presents the reader with a single image
and asks them to interpret the meaning. I this about breaking free? Escape?

Figure 22

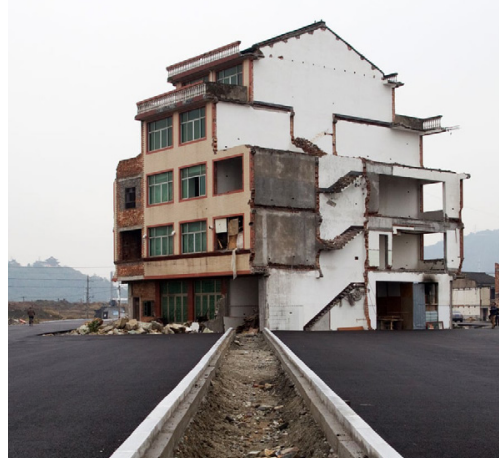

China Nail House

The nail house has become widespread
throughout China with owners of the strectures refusing to move to make way for new construction projects until they receive wha Figure 23 any awareness or positive social progress that the protest at tempted to inspire.

Inspiration

I have always been fascinated by Chinese "Nail" House Protests. Despite China being a communist country, it has stron property rights. The Government has great difficulty expropriating private property for public use. ${ }^{28}$ The images of single houses standing in the middle of a new road is ridiculous, but inspiring, clearly have the ability to raise awareness, however, are disruptive to traffic and progress. The imager of the house from the Pixar film "Up" has always stuck with me. The idea that once a house and its occupant is no longer welcome on its site, it can simply float away to a better place is a tragically impossible yet romantic thought. This theme is similarly used in Chris Van Allsburg's children's book, The Mysteries of Harris Burdick

\section{Intent}

What could be a conspicuous, "constructive" form of protest to a particular social issue (in this case housing unaffordability) that both "right" and "left" winged people would stop and consider? What could touch a cord with both opposing sets of political sensibilities? 


\section{Built Environmen}

Inspired by the noted precedents, I envisioned a nail house built on scaffolding to prevent traffic disruption. The resourcefulness, ingenuity, and hard labor to create such a structure would likely ring well with the conservative set, while the highly visible statement against un-affordable housing, historical redlining, suburban white flight, is hopefully a strong social critique. Built by re-assembling a house slated for demolition, it avoids the implication that others property be taken or redistributed. The traditional vernacular of the house is meant to represent the quintessential American dream that all families regardless of race or background should have the right to strive for. This reasonable and relatable dream is mean to engage the empathy of the viewer. Initial sketches considered that the family built the house to take up a defensive position to fend off police assault, which included modifying a vehicle to achieve this. This was discarded as I felt it was on the nose and a "one liner". The practical and metaphorical meaning of a house with no site can act as metaphor for many social injustices, however I kept the vehicle image at the end of the narrative to add intrigue.

\section{Characters /Narrative}

The characters are a young African American family. The United States has a history of racial injustice towards African Americans in regard to discriminatory practices in housing markets, such as the redlining phenomenon. As an example, in Atlanta in the 1980s, investigative reporters showed that banks would often lend to lower-income whites, but they would refuse loans to middle-income or upper-income black families. ${ }^{29}$ There have been cases of racial restrictive covenants in property deeds, banning sale of homes to non whites.

${ }^{30}$ As such, it is indisputable that African Americans have very good cause to protest hous- ing inequity. In the narrative, the couple is forced out of their rental property by a new own

er. It details the coupless survivor attitude, resilience, and resourcefulness to take matters into their own hand to solve their totally unjust situation. As their act of protest is respectfu of the rights and spaces of others (does not block traffic, seize, or vandalise property), the public would likely not pressure the authorities to remove it, and may want to support it.

\section{Representation}

The final rendering is an earlier perspective style I experimented with prior to evolving to the planimetric composition of the other fictions. The image is symmetrical, and character focused. I believe it works reasonably well, however if I could start over I would include more animation, lighting atmospheric effects, and more care in the detail of the surrounding structures.

\section{Final Reflections}

This is a constructed protest that hopefully both "sides" of the political conversation could consider. Given the extreme partisan nature of American politics, perhaps this is the form of critique that could bring lawmakers across the aisle, to recognize their common hopes and dreams, and drive social positive change. 


\section{DETROIT MICHIGAN}

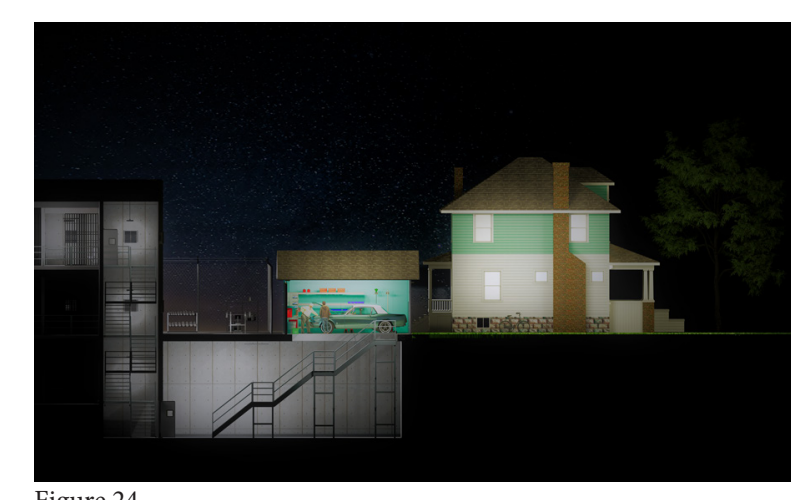

News

The United States has more prisoners per capita than any country in the world. About $20 \%$ of these are private prisons, who pay millions of dollars to lobbyists to influence legislation for longer sentences. ${ }^{31}$ What incentive do these prisons have to rehabilitate their inmates? This is simply eliminating a potential repeat customer. Protests concerning racial injustice point out the disproportionate number of incarcerated black men affected by this flawed system. ${ }^{32}$

The prevalence of depression and loneliness among older isolated adults, often in long term care facilities, has increased during the Covid 19 pandemic. ${ }^{33}$ The stories of these men and women dying alone due to the incompetence of the government to provide a standardized, safe, and sterile living environment is a black eye on the face of our entire society.

\section{WFOXNEWS}

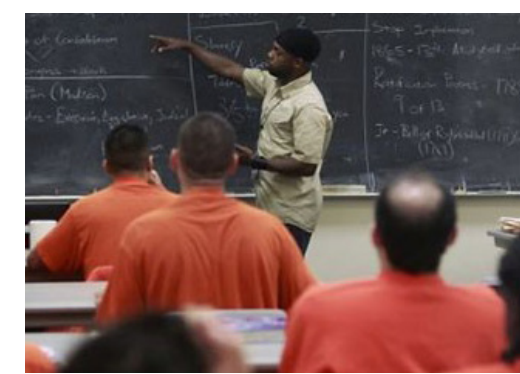

Private prisons are a multibillion-doar industry - and growin

Liberty Vittert - December 19th, 2018 80,000 beds supported by the government it's collecting about $\$ 1.8$ billite per year from the government. Business is booming indeed - thanks to the American taxpayers Figure 25

\section{MarketWatch}

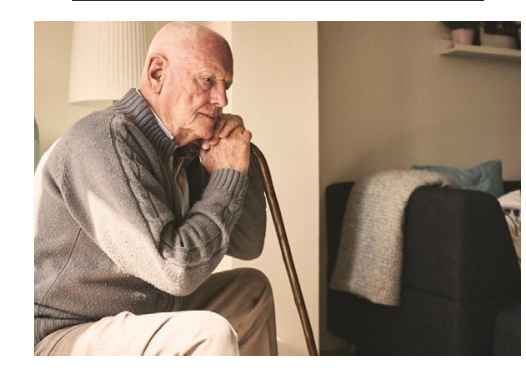

I'm very lonely and depressed'nany nursing home residents say the iz Seegert- October 12th 2020 Wéve come a long way in understanding derstand that the quality of life is paramount or people later in 1

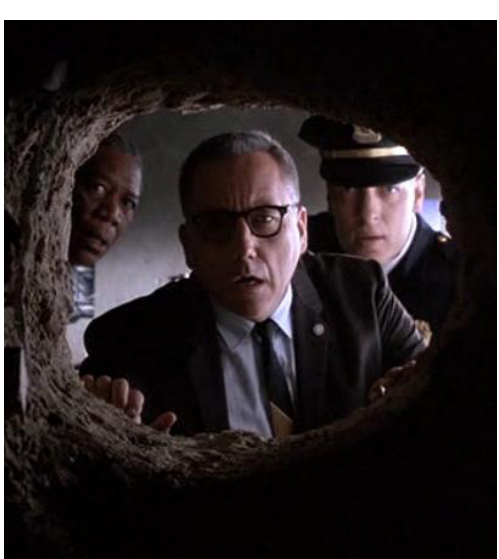

Frank Darabont (1994) Darabon's "The Shawshank Redemption" addressed the institutionalization of prisoners beyond the prison walls In this scene the prisoner escapes through a tunnel dug over years and hidden behind a poster Figure 27

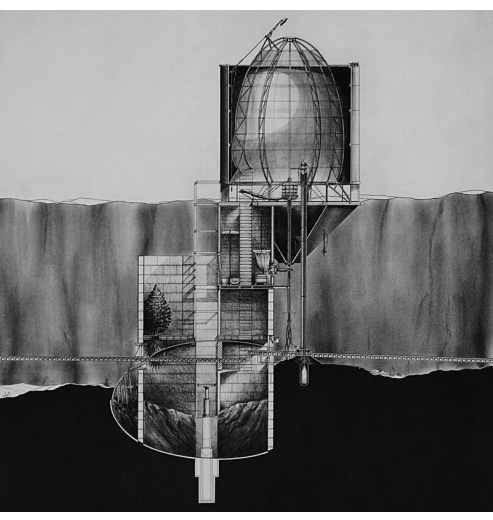

Douglas Darden (1988) Darden's "Oxygen House" has a somber inter
woven theme of death which has the effeter of engaging and connecting with the viewer Figure 28

\section{Intent}

It occurred to me that these two demographics groups: the inmate and the tossed aside senior citizen had something in common. They have both been failed by our society. So, as the age-old proverb goes, the enemy of my enemy, is my friend. How could these two "inconvenient" demographics join forces to break free from their owns form of imprisonment?

\section{Inspiration}

Frank Darabont's The Shawshank Redemption addresses the institutionalization of prisoners and the fleeting attachmen with the world beyond the prison walls. ${ }^{34}$ It reinforces the dehumanizing conditions of prison and spatializes, in a famous scene, that sometimes the only freedom from injustice is to dig yourself an escape tunnel with a rock hammer. Douglas Darden's Oxygen House has a somber interwoven theme of death which has the effect of engaging and connecting with the viewer through empathy. ${ }^{35}$ This works sectional quality was the basic inspiration for the composition of the final image for this project. 


\section{Built Environment}

The choice of the archetypal suburban home as a setting for this fiction is intentional. What are the suburbs really about? I would argue that they are about turning our back on a broken society to create an exclusionary utopia at a distance from the problems of the inner city. ${ }^{36}$ The constructed fictional environment is the deliberate uncomfortable paring of opposing spaces of house and prison. It intentionally shows the worst nightmare of the typical suburban dweller, the prospect that a prisoner could find their way into their house, their sanctuary. It asks the viewer to consider the selfishness of this all too typical urban planned segregation.

\section{Context / Themes}

The project is set in the socio-political context. Themes of escape, freedom, good vs evil, light vs dark, father vs son, loneliness, and the fundamental need for human contact is interwoven in the narrative and imagery. The stairs leading from the prison to the garage represent the ascent from hell. The vintage car is a quintessential object of interest involved in a-political, cross-cultural male bonding.

\section{Characters / Narrative}

The characters of the young wayward man and the old obsolete man are archetypal. Society has abandoned them both, so they form a mutually beneficial relationship. One regains their humanity, the other, their sense of utility.

\section{Representation}

The image is aimed at contrasting light vs. dark, institution with home, loneliness vs companionship. The sectional representation allows the viewer to follow the path of the prisoner who has left his cell to escape to the garage. The house itself emits an unnatural warming light, representing warmth and welcome.

\section{Final Thoughts}

Our society segregates. We rely on government and institutions to store our law breakers and inconvenient elders out of sight out of mind until they expire. I wished to propose a speculative fiction that took an alternate approach. What if each individual in our society made it their personal responsibility to aid in the rehabilitation of the fallen or misguided? What if we facilitated the living of our elders' sunset years with purpose and companionship? What if we lent a hand to our fallen, one on one, man to man? 


\section{SONORAN DESERT MEXICO}

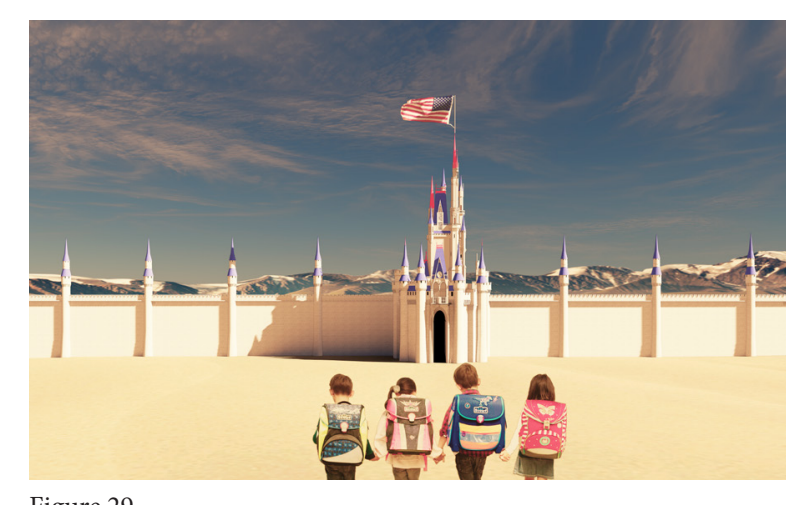

News

In April 2021 nearly twenty thousand children arrived at the US- Mexico border. Half of the children, who hail primarily from Honduras, Guatemala, El Salvador, and Mexico, have traveled without their parents. ${ }^{37}$ Under President Trumps "Zero Tolerance" policy to deter illegal immigration, authorities separated children and infants from parents or guardians with whom they had entered the US. The plan had no measures to reunite separated children. ${ }^{38}$ Images of children in cages seem impossible to believe.

Inspiration

Often in fictions with child characters in distress, the child will create an imaginary world to escape to. "Go to your special place" is a common phrase a mother might use to calm her child. Sean Baker 2017 film “The Florida Project” follows two 8-year-old girls living in poverty in a pastel motel just outside of Disney World. The film focuses not on their de-

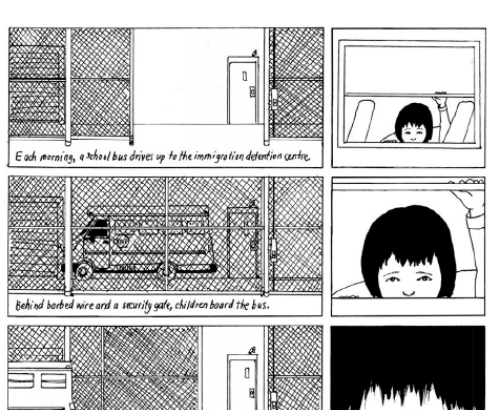

Ting Chak (2014) Chak's graphic novel "Undocumented: The Architecture of Migrant Detention" situates
spatializes, and confront the silenced voices spatializes Figure 3

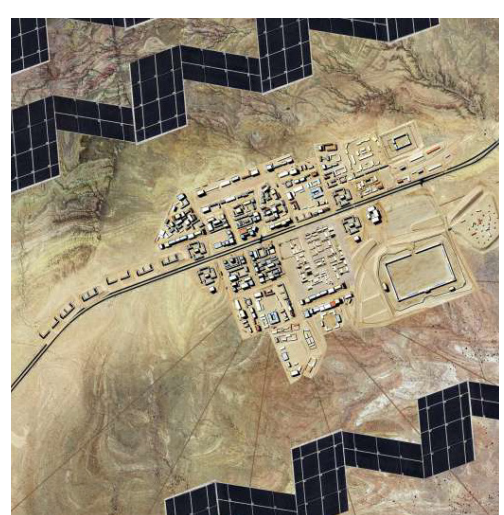

Madeline Ashby (2014) In Ashby's "By the Time We get to Arizona" ity television-style competition, with newl arrived contestants living and working untotyping community.

Figure 33

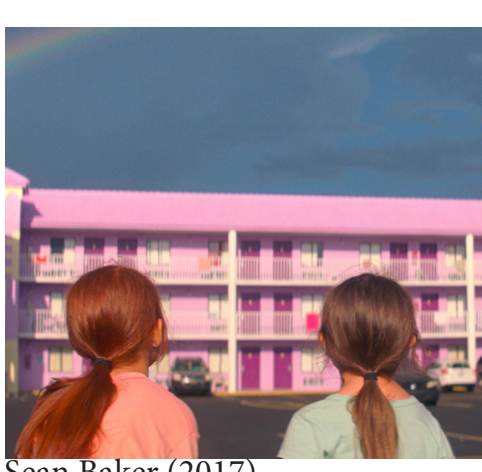

Mexico sees massive increase in hildren near US border: UNICEF Daniel Becerril - April 19th 2021 Half of the children, who hail primarily from Honduras, Guatemala, ES Salvador and
co, have traveled without their parents. Figure 3 spair, but on the power of childhood imagination. The girl create their own imaginary worlds as a form of escape. Aaron Becker's children's book, Journey follows a child who, bored and isolated, draws her own door to escape into an imaginary world of her own construction. In both cases, children devoid of resources, default to creating their own constructed environment that exists solely in their minds.

Ting Chak's graphic novel Undocumented: The Architecture of Migrant Detention situates, in the Authors words "spatializes, and confronts the silenced voices detained". ${ }^{39}$ In Ashby's By the Time We get to Arizona, U.S. Mexico immigration has become a reality television-style competition, with newly arrived contestants living and working under constan surveillance in a planned prototyping community.

\section{Intent}

I asked myself how these child refugees might use this technique in order to endure their ordeal during their journey. What imaginary-built environment would they create to keep up positive spirits and moral while facing adversity along the way? 


\section{Built Environment}

A castle wall, or fortress that one must pass is a trope in many adventure novels. I wish that the castle wall and its significance remain semi ambiguous, with many possible tandem interpretations. Is it representing the "special place" created in the minds of the children to endure their journey? Does it represent a physical manifestation of an imaginary mass adopted false narrative used to replace the un-palatable truth of a border with children in cages? Is it an actual future construction by a future second Trump term to complete his promise of a beautiful wall in a style appealing to his cultureless base? I will leave it ambiguous.

\section{Context / Themes}

The story is embedded in a geopolitical context, in particular US policy on immigration. The positive common thesis theme of self reliance and determination is present; however it also touches upon themes of deception, and mass delusion

\section{Characters / Narrative}

The narrative is meant to be ambiguous and open ended. It provides some backstory, explaining why the children are leaving their homeland and why they are alone. It is meant to be ambiguous as to whether it is tragic or hopeful. Did the children make it? Or did they lay down and die of exposure having only envisioning the stories conclusion in their minds?

\section{Representation}

The imagery is a based on a SketchUp model rendered in Enscape. It employs false scaling to compensate for the lack of perspective and positions the viewer in the video game standard 3rd person role playing vantage point to allow the viewer to embody the character themselves.

\section{Final Reflections}

am not satisfied with the final rendering. The shadowing and mountain range could be improved. That said. I believe it gets the intended message across. It hopefully is a double-edged sword of sorts. While celebrating the power of childhood imagination, it criticizes and brings light to an ongoing occurring tragedy. 


\section{LOS ANGELES}

CALIFORNIA

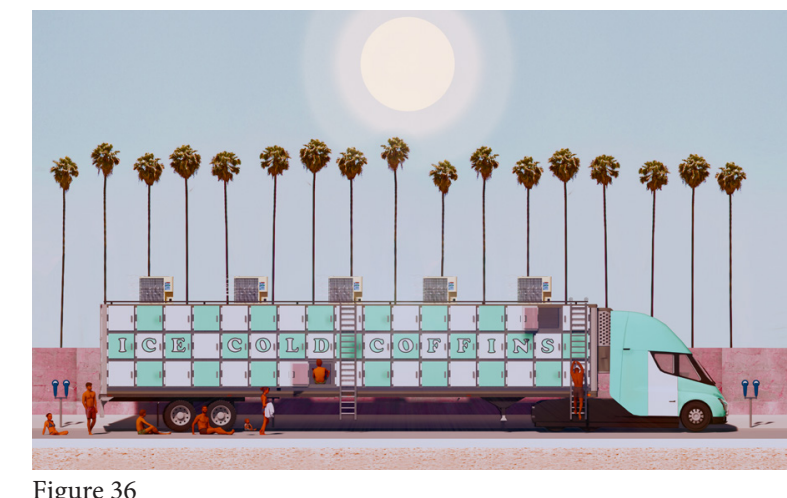

News

\% REUTERS

California was a daily headliner of 2020 with stories detailing mass homelessness, forest fires, record heat waves, resident and business exodus. ${ }^{40}$ One article detailed the life of a young man who pays $\$ 1200$ USD a month to rent the top bunk of a bunk bed in a pod share in Los Angeles. ${ }^{41}$ A Google street view road trip of skid row Los Angeles shows a tent city having sprung up in the past 5 years. This housing crisis is occurring at a time when climate change has devastated California. Wild fires are rampant, record heat waves and deaths from "EHE” or Environmental Heat Exposure are rising at alarming rates. ${ }^{42}$

Inspiration

The 1973 film Soylent Green, which details a dystopian future devastated by an unnamed environmental catastrophe, where suicide is encouraged, and food is derived from human corpses although admittedly silly, its visual representation of

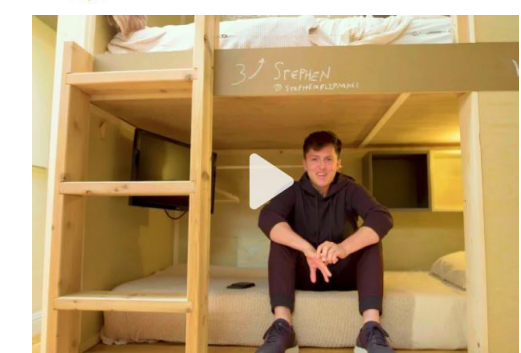

This bunk bed is $\$ 1,200$ a montl, This bunk bed is $\$ 1,2$
privacy not included

Anna Bahney - July 5th 2019

PodShare membership allows you to sna tions across Los Angeles and one in Sa ancisce.

ON BUSINESS is regarded here as consisting of two major
components: a living-pod and attached ma(2)

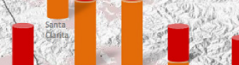

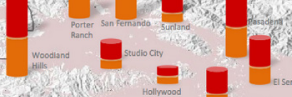

mats

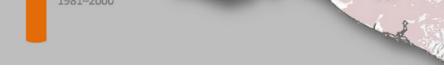
$\mathrm{N}$ warns of climate 'abyss' as 2020

Kate Abnett- April 14th 2020 Death Valley in Clforniz also recorded he world's highest known temperature for at least 80 years of 54.4 degrees Celsius gure 38

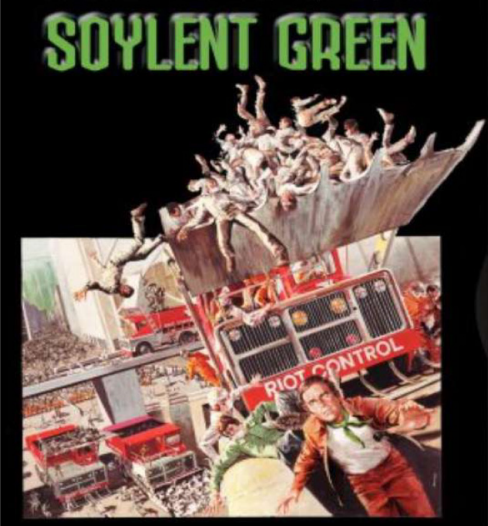

Richard Fletcher (1973) Metcher's "Soylent Green" brings us to the year , w mate catastrophe have caused severe worldwide shortages of food, water and housing. Figure 39

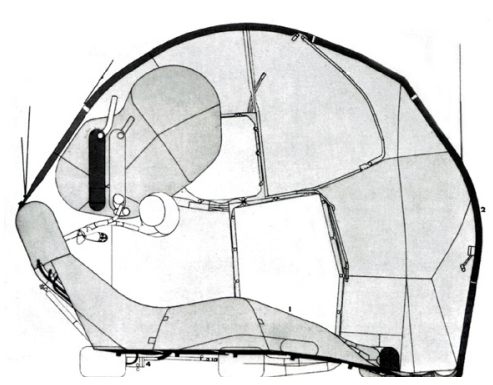

David Greene (1966)

"The Living Pod" is an inventive project by Figure 40

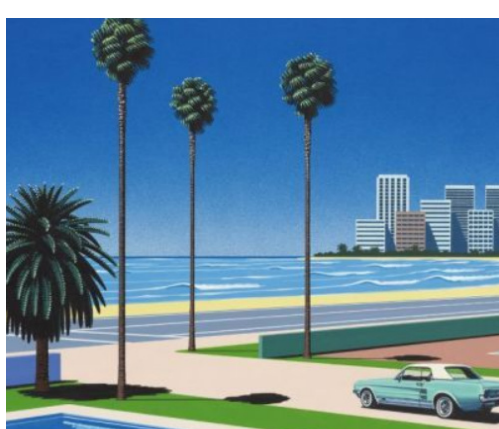

Hiroshi Nagai (2015)

Negais "untitled" feature Americana whic though visually appealing, "simultaneously
evokes a sense of isolation and dread among capitalist wo th Figure 41 life without the resources we take for granted had an effect on me. David Greene experimented with ultra minimalis living pods with attached machines. A life that consumes the absolute bare minimum that the body needs to maintain its metabolic functions may be a necessity in a resource limited future. As the intervention is to be in California, I feel it should have that certain "Je ne Sais Quois" that fetishizes the appeal of California itself. The aesthetic of the illustrations of Hiroshi Nagais seem to fit the bill.

\section{Intent}

I wished to explore how the young millennial pod dwellers of California might leverage their particular skills to adapt their environment to deal better their situation.

\section{Built Environment}

The story includes two built environments, an automobile converted into a fourplex, and the renovated Tesla Sem Both spaces are representative of extreme re-use and up-cycling, which is part and parcel to the minimalist mantra. The conversion of a police car and morgue into housing is an intentional contrast, as it turns items associated with oppression and death to ones of freedom and life. Its signage fo- 
cused cladding is inspired by the bright, auspicious "Googie" Architecture of 1960s California roadside establishments.

\section{Themes/ Context}

The story is in a social and environmental context. It champions a libertarian uprising through cooperation, crowd sourcing and ingenuity. It is inspired by the mantras of the minimalist movement, namely a low consumption, anti consumerist lifestyle

\section{Representation}

I attempted to capture the visual language of artists such as Hiroshi Nagai, David Hockney and Edward Hooper. I tried to represent the visible heat, humidity and pastel palette that is the hypnotic everlasting appeal of California.

\section{Character and Narrative}

The characters are effectively a caricature of the quintessential millennial. This demographic, with their crowd sourcing, coding and engineering prowess, marketing know-how, crypto-enthusiasm, love of the kitsch and the ironic, I suspect have a trick or two up their sleeves. The narrative details the required backstory, and the journey of our protagonist

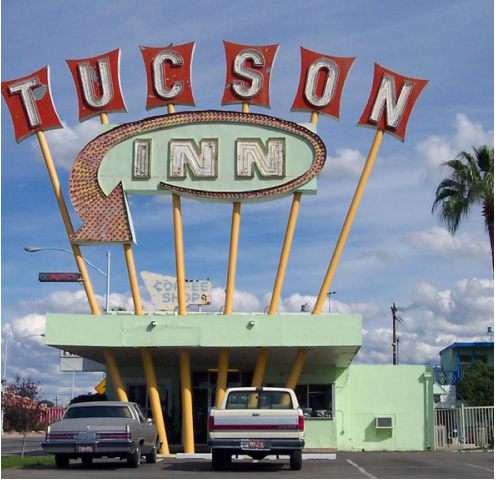

Anne Rysdale (1953)

"The Tuscon Inn" "Visionary Googie designThes in 1986 " "We were just tesigning thels sell hamburgers." Figure 42

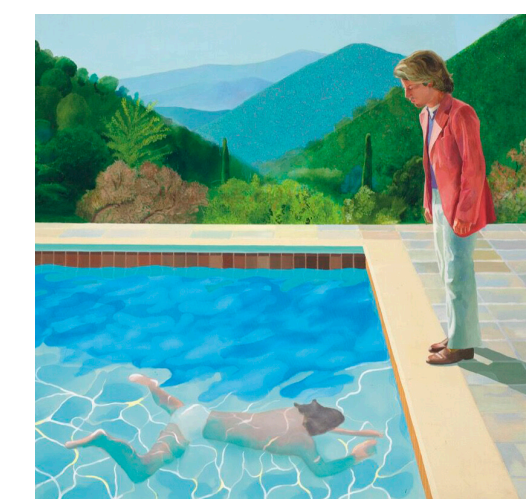

David Hockney (1972) Hockney's "Pool with Two Figures" promoted
an aesthetic of an appealing California life

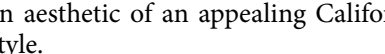
Figure 43 entrepreneurs while they start their own business, and dissociate with the socialist state they occupy. The narrative satirizes the upper limit of government mismanagement and poor decision making (such as responding to an increase in heat exposure deaths by investing in new morgue infrastructure rather than housing). This is perhaps the beginning of a new barter grassroots economy that operates autonomously, (blood for cooling?), the early days of California's rebellious return to Reaganomics ${ }^{43}$, a deregulated economy that allows entrepreneurs to strive and thrive.

\section{Final Reflection}

I believe of all 6 narratives, this was the most successful. The characters are relate-able, the built interventions seem plausible, and I feel it makes a strong statement and brings awareness to the colliding environmental and social struggles in California. It is a constructive non disruptive protest, highly embedded in speculative forms of inhabitation and representative of the themes and context I wished to explore in this thesis. 
MANHATTAN

NEW YORK

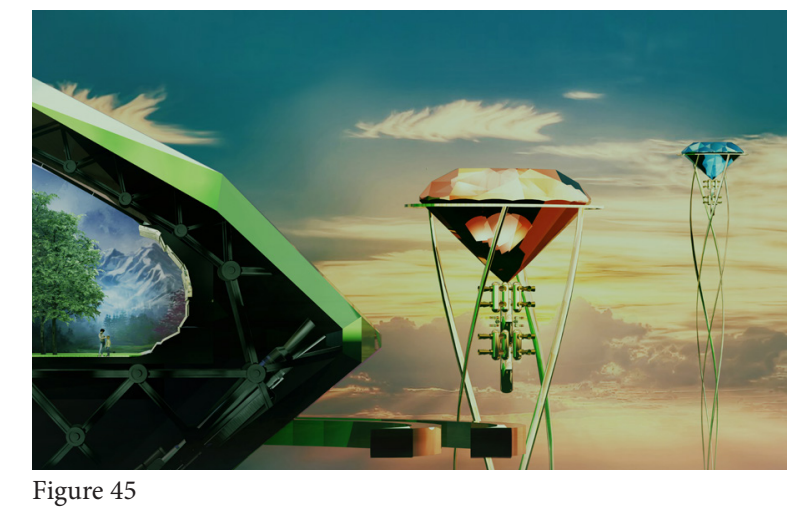

News

Reporter Emily Brumfeild-Hessen notes "Millions of Americans linger in a delusional reality. In their world, their leader won, but his victory has been denied by traitorous enemies of the people." ${ }^{44}$ The Washington Post Fact Checker has documented over 30,000 false or misleading claims made by Donald Trump during his presidency ${ }^{45}$, however his communications director Stephanie Grisham has stated that he doesn’t lie. ${ }^{46}$

Vanity Fair Magazine recently published a photo of the Trump family at their home in Trump Plaza. The photo demonstrates that Trump does not only sew a false reality to control his base, but he also constructs a physical one, in this case a gilded cage for wife and son. This no doubt is a common observation, given the "Free Melania" meme that has circled social media. ${ }^{47}$
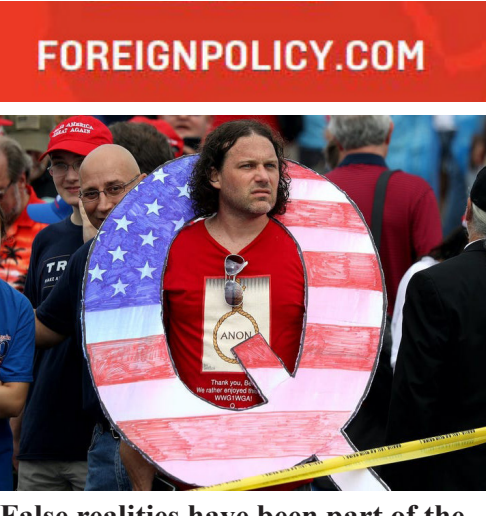

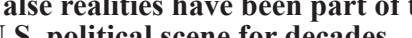
Emily Brumfeild- February 26th, 2021 Millions of Americans linger in a delusiona Figure 46

\section{NBC NEWS}

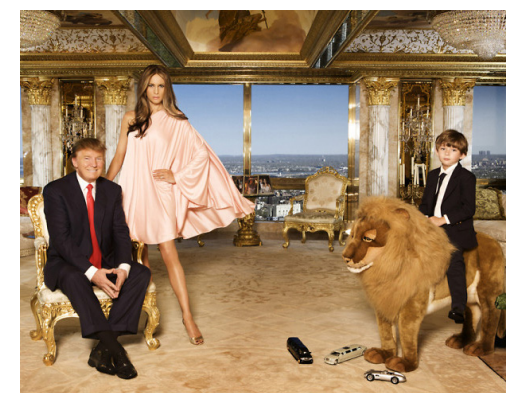

News media paid Melania Trump thousands for use of photos in 'posiAndrew W Lehren - July 2nd 2018 Melania Trump has earned six figures in which major media orgnizato gagench indirectly paid the Trump family despite a requirement
Figure 47

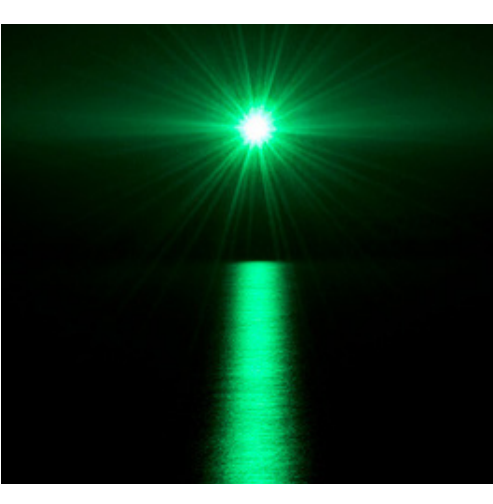

F Scott Fitzgerald (1925) Fitzgeralds' "The Great Gatsby" uses a green
light in the distance representing desire and light in the distancer representing desire and
the seeming impossibility of achieving the materialistic American Dream. Th"
seems at once "a minute and far away" Figure 48

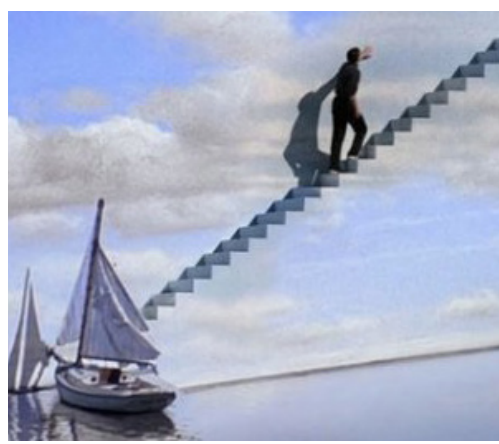

Peter Weir (1997)

Weirs "The Truman Show", features the titu-
lar character trapped unknowingly in a brat set populated by actors for a television show about him. He is living in a fictional reality Figure 4

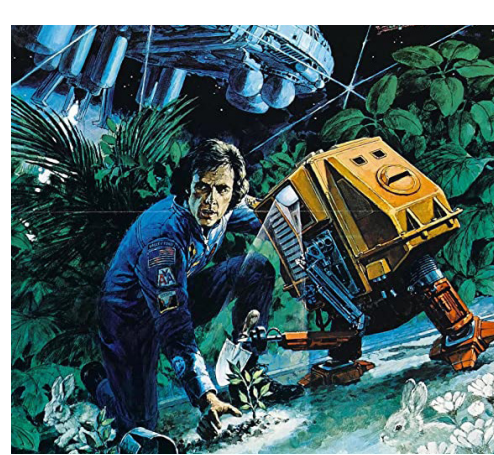

Douglas Trumbull (1972)

Trumbull's "Silent Running" envisions a dystopian future were the last remaining vegetation
is preserved inside geodesic domed spaces stations.

\section{Intent}

I wished to produce a speculative fiction that contemplated the most extreme outcome of this trajectory of constructing false realities. What could be the utmost expression of wealth, materialism, and excess? How could its captive in habitants resist and break free from this intellectual and physical prison?

\section{Inspiration}

The inspiration for this fiction came from multiple sources. F Scott Fitzgerald's The Great Gatsby uses a green light in the distance representing desire and the seeming impossibility of achieving the materialistic American Dream. ${ }^{48}$ In the 1998 film the Truman Show, the titular character was trapped unknowingly in a large set populated by actors for a television show about him. A final inspiration for this speculative future is the 1972 film: Silent Running. The plot follows a crew tending to a botanical garden sealed within geodesic dome like spaceships the earth having become unsuitable to sustain it. This film inspired the interiors of the built environment. 


\section{Built Environmen}

The project is set in New York, so what comes after the Art Deco reinterpretation? I Suppose it would have to be Art Nouveau. What is the absolute pinnacle statement of opulence and excess? It has to be diamonds in the sky. These tropes forms the basis of the exterior of the space, which, like the typical suburban McMansion, is solely concerned with how it asserts its status to its surroundings. The interior realm will have no dialogue with the "real" world. It will sew the utmost false environment possible. I felt that an artificial forest and log cabin would best represent this.

I wished to make conspicuous use of emerging technology to bring this project to life. This is included to represent the ongoing dilemma with capitalism. The ultra rich create objects that advance technology that can trickle down to more practical use, and their monuments to themselves do provide the landscape with interesting postcard fodder and popular selfie backdrops.

The towers that I envision will be of a top-heavy geometry that will present many challenges. They will be built primarily from Graphene Fiber. Graphene is the strongest material ever discovered, having a strength to weight ratio of approximately 250 times that of struc tural steel. ${ }^{49}$ Graphene also contains elastic properties, being able to retain its initial size after multiple stress cycles. Due to its properties, the towers can weigh significantly less, and have much more slender forms. Tensile support cables made from this material would be very thin and still provide adequate strength, while being practically invisible from a distance. Sway due to wind force is an engineering challenge in tall structures. Traditionally tuned mass dampers are utilized however these likely would be inadequate in this super slender top-heavy tower. The tower will use a technology pioneered by SpaceX which uses cold gas thrusters to stabilize its rockets during landing. An array of wind pressure sensor will allow controlled continuous micro thrust bursts through nozzles pointed in all orientations to continuously equalize the wind pressure and keep the living mod immobile. Due to its unapologetic blatant monumentality to self indulgence, the towers will be at risk of attack. In the event of a non-survivable attack that would cause catastrophic collapse, a ballistic parachute system allows the occupied space to fall to the ground safely.

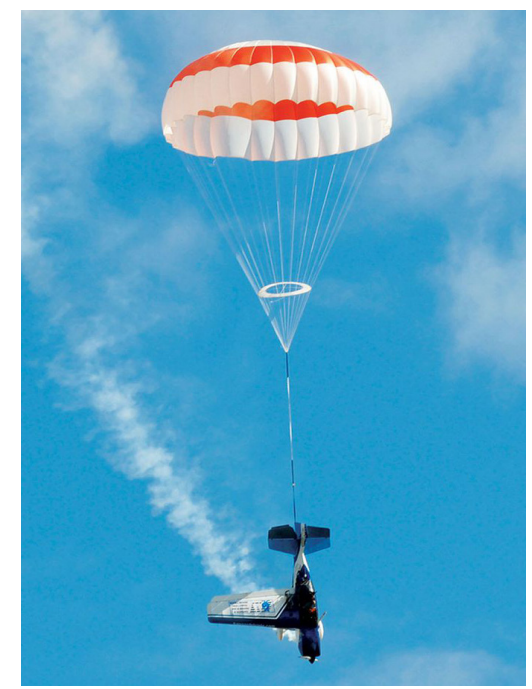

Figure 53: Ballistic Parachute

\section{Representation}

Experimented with multiple alternate representational strategies. A fictional news article that predates the towers eventual construction gives some backstory and details to present a "puzzle piece" to the reader to assemble their interpretation of the narrative. The Instagram account of the protagonist, Natasha, is provided to allow the reader to put together a spatial picture of her "gilded cage". I produced technical annotated line drawings to detail the engineering features of the tower. In the end I reverted back to using primarily a single rendering for the final composition so that there would be consistency in the final set of narratives. 
The characters, Natasha is a stand in for Melania Trump. The narrative introduces the extreme technology developed for the tower and some backstory. The text attempts to allow the reader to experience the visceral qualities of inhabiting and escaping the space.

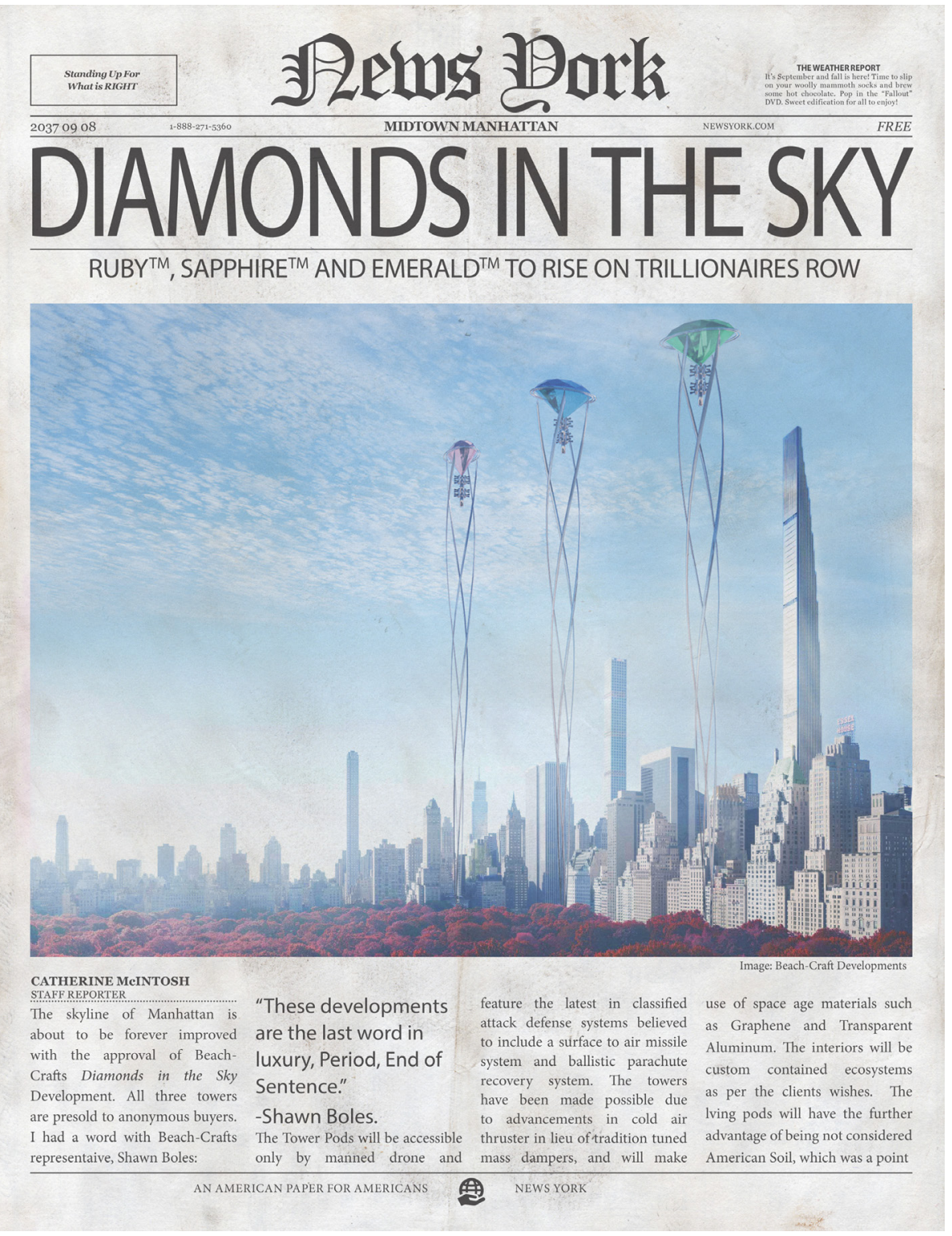

A fictional news article that predates the towers eventual construction gives some backstory and details to present a "puzzle piece" to the reader to assemble their interpretation of the narrative. Figure 5
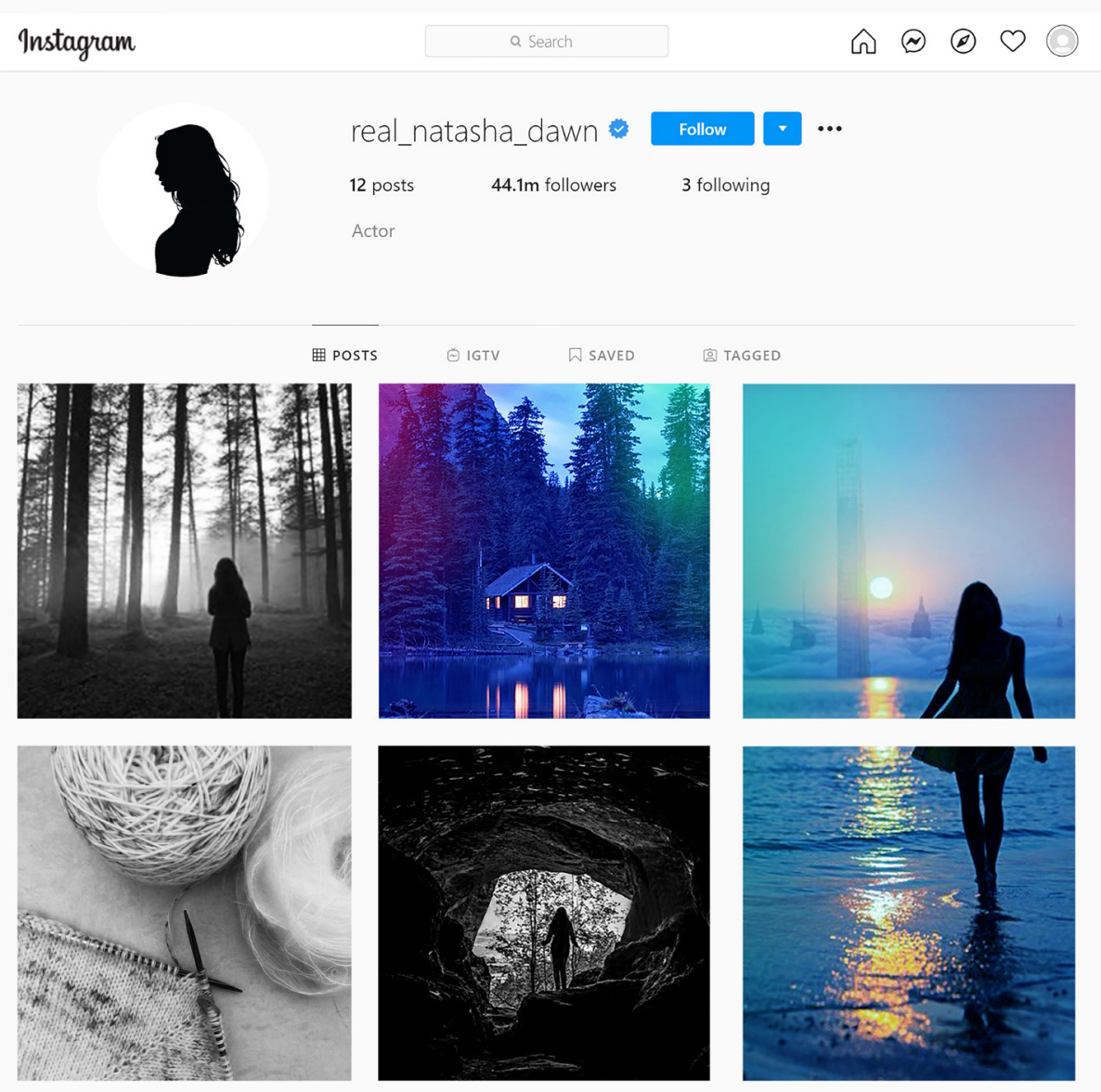

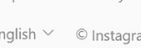

The Instagram account of the protagonist, Natasha, is meant to allow the reader to put together a spatial picture of her" gilded cage" Figure 55

Final Reflections

2020 saw the disastrous effect of mass delusion, culminating on the storming of the US

Capital after Donald Trumps election loss. I believe this sewing of these false narratives is driven by the desire to control others through fear. The construction and imposing of false environments and realities onto others sees an extreme expression with this project. 


\section{Process Work}

This section includes imagery to detail the process of producing the narratives visual representations. The process begins with rough pencil sketches to get the idea down and test if it has legs. As the pencil sketches advance, the final composition is considered. Once the design is complete, it is modeled using Sketchup. Props are downloaded from 3D warehouse to add realism to the scene. Multiple vantage points are tested. Lighting is added and tested using Enscape. Clipart is added to the model itsef so that it will produce shadows and absorb light. Test renders are made, printed, and sketched over in pencil to quickly test revisions. The final image is rendered in Enscape, and color corrected, modified in Illustrator

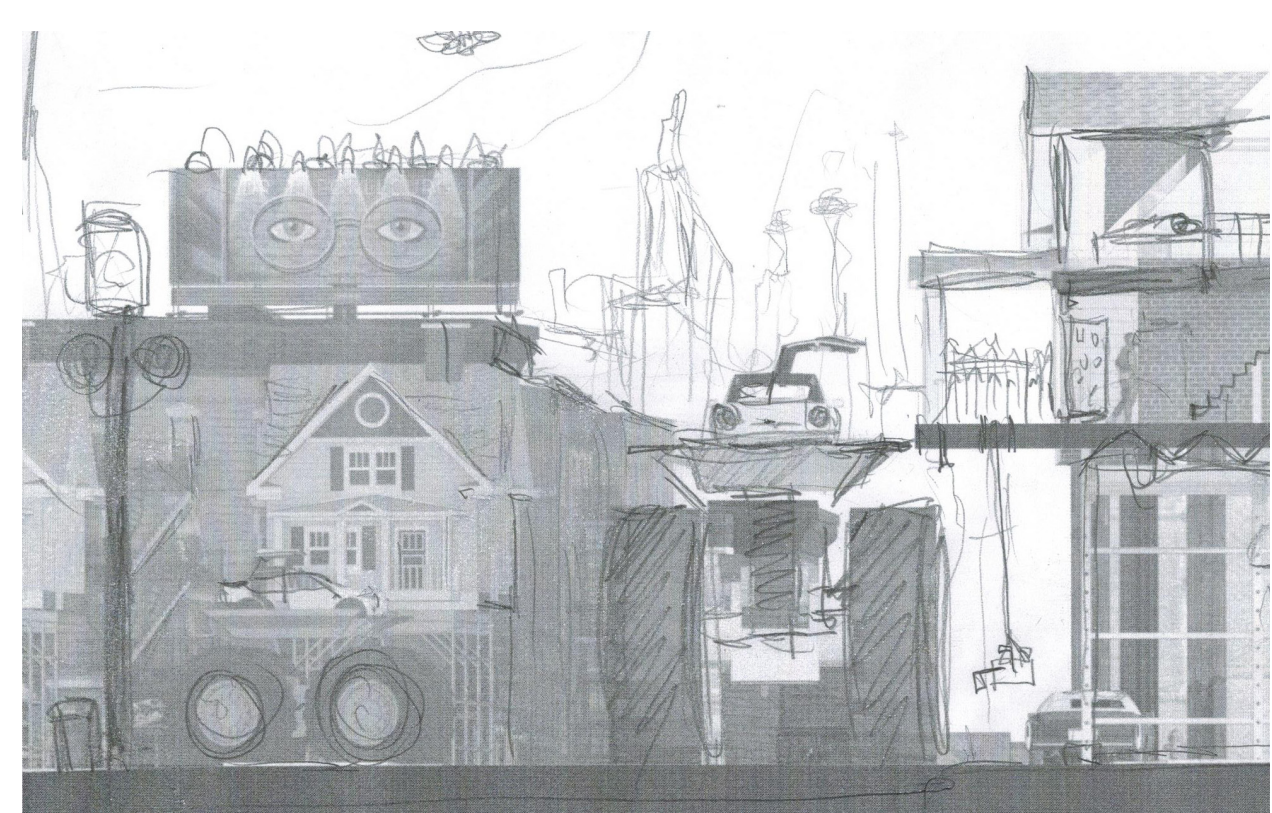

Ottawa, Ontario - This is an example of a sketchup model rendered in Enscape, printed, with pencil sketches 作 Figure 56

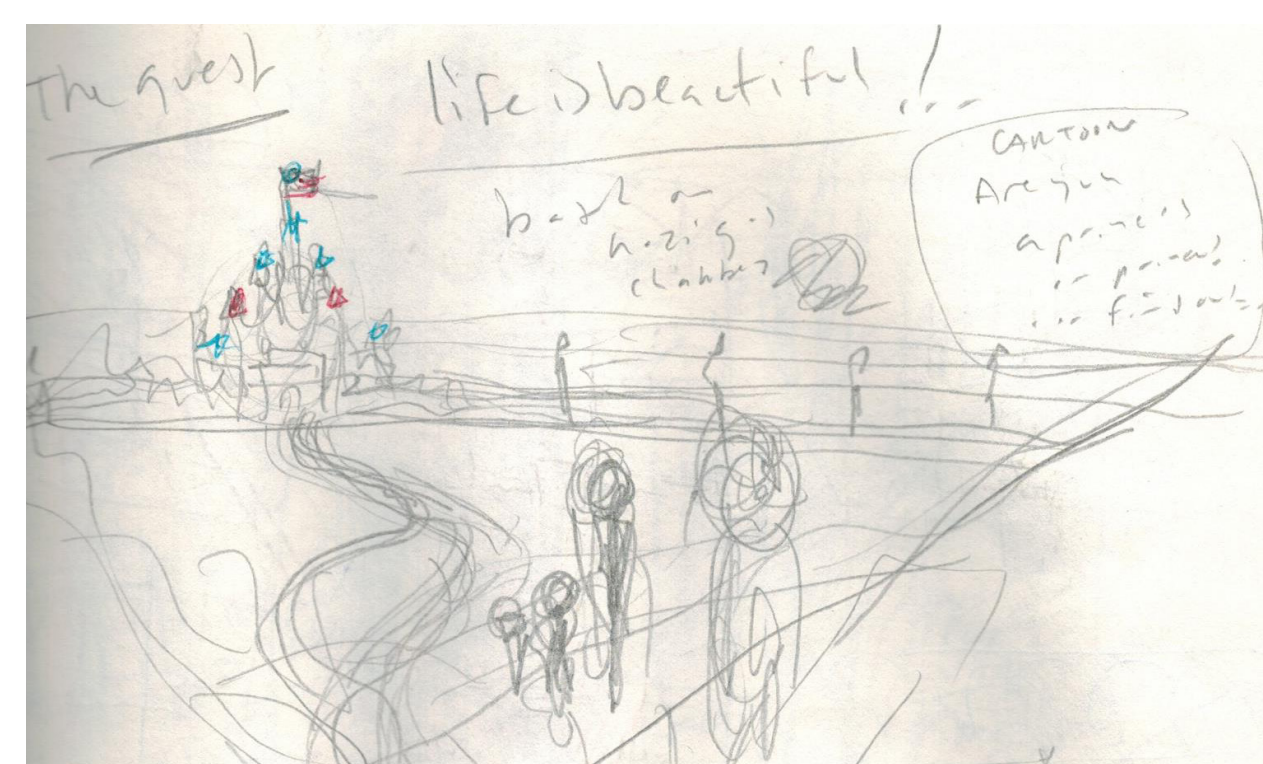

Sanoran Desert - Mexico - This was the very first sketch made for this project. At this stage, the sketch is made quickly simply to preseve an idea
of characters, and planes of view. Figure 57

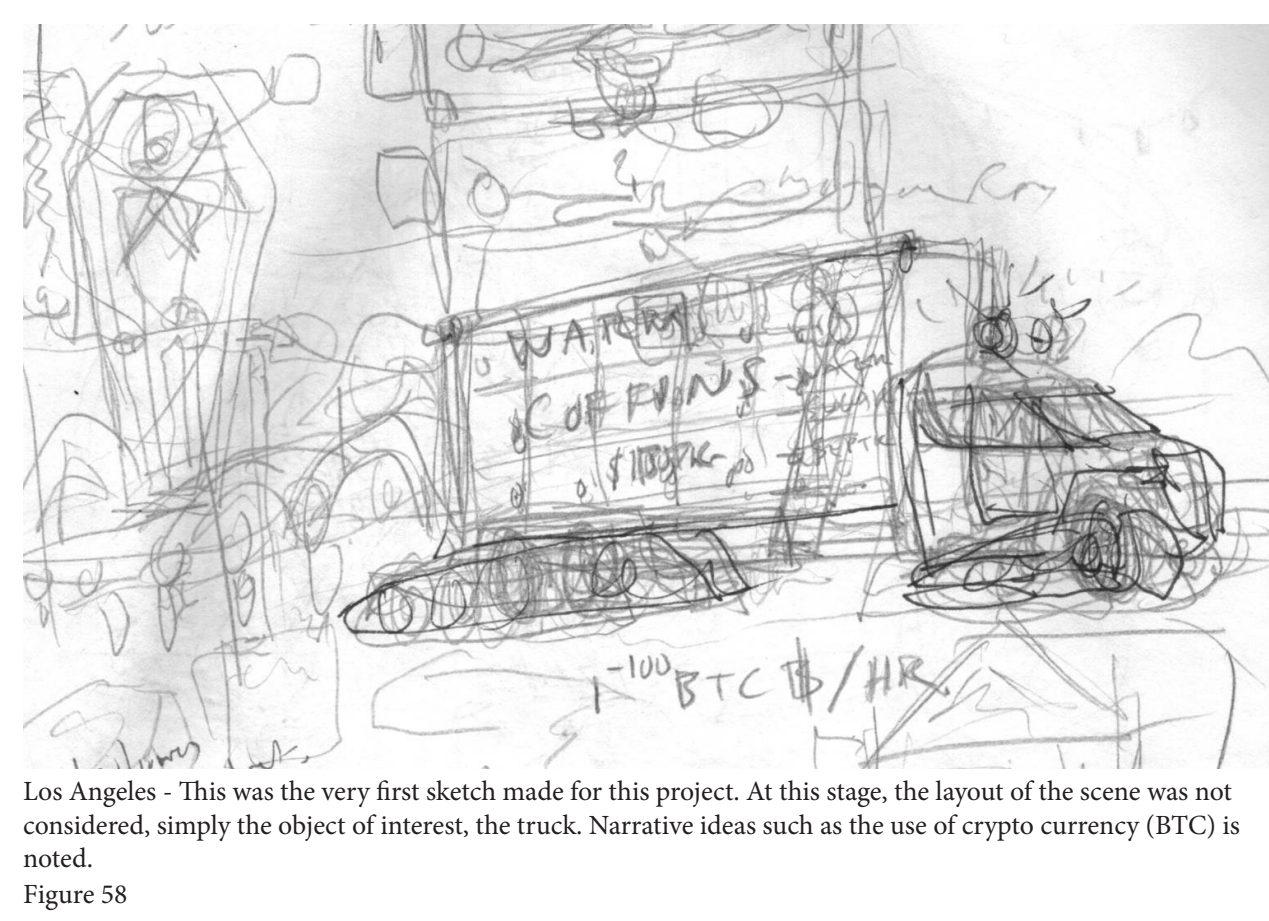




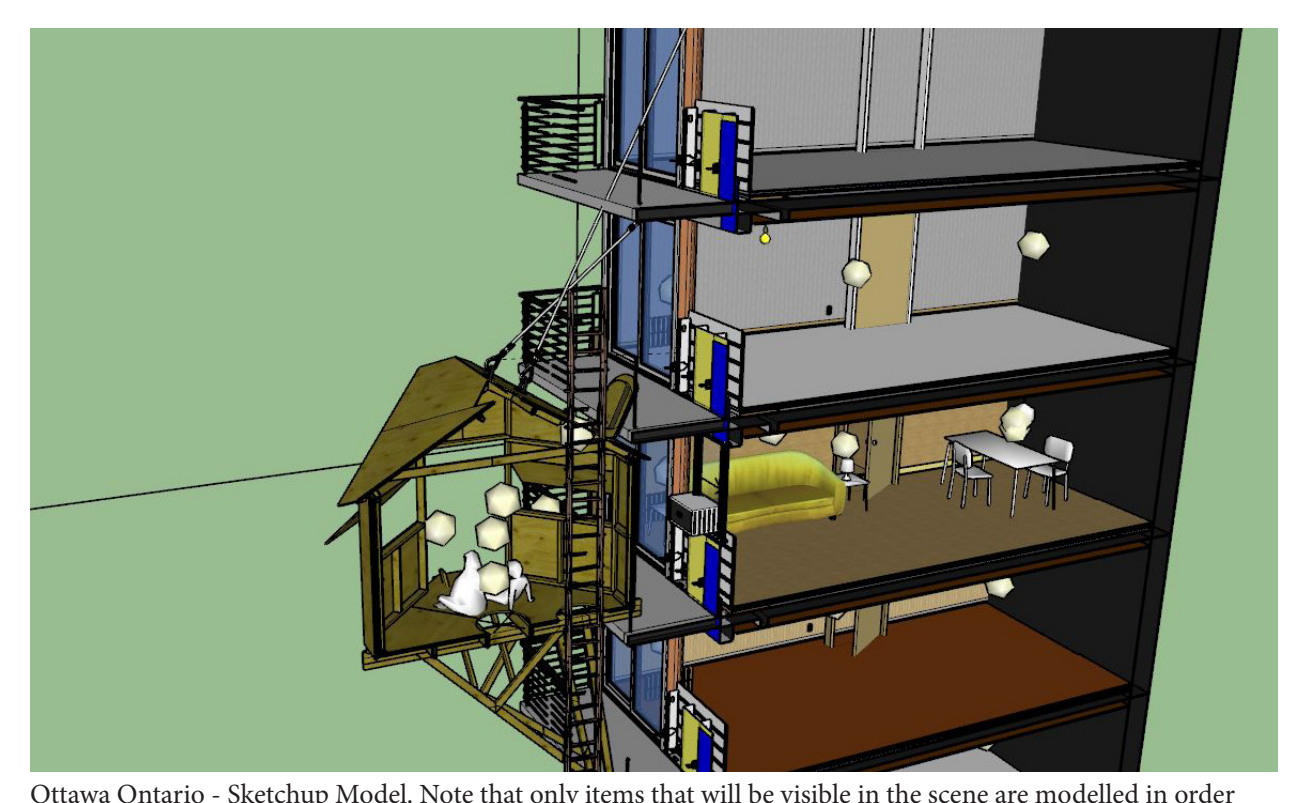

Ottawa Ontario - Sketchup Model. Note that only items that will be visible in the scene are modelled in order
to save time and memory . White balls apartment module was only modeled once, and then repeated.

Figure 59

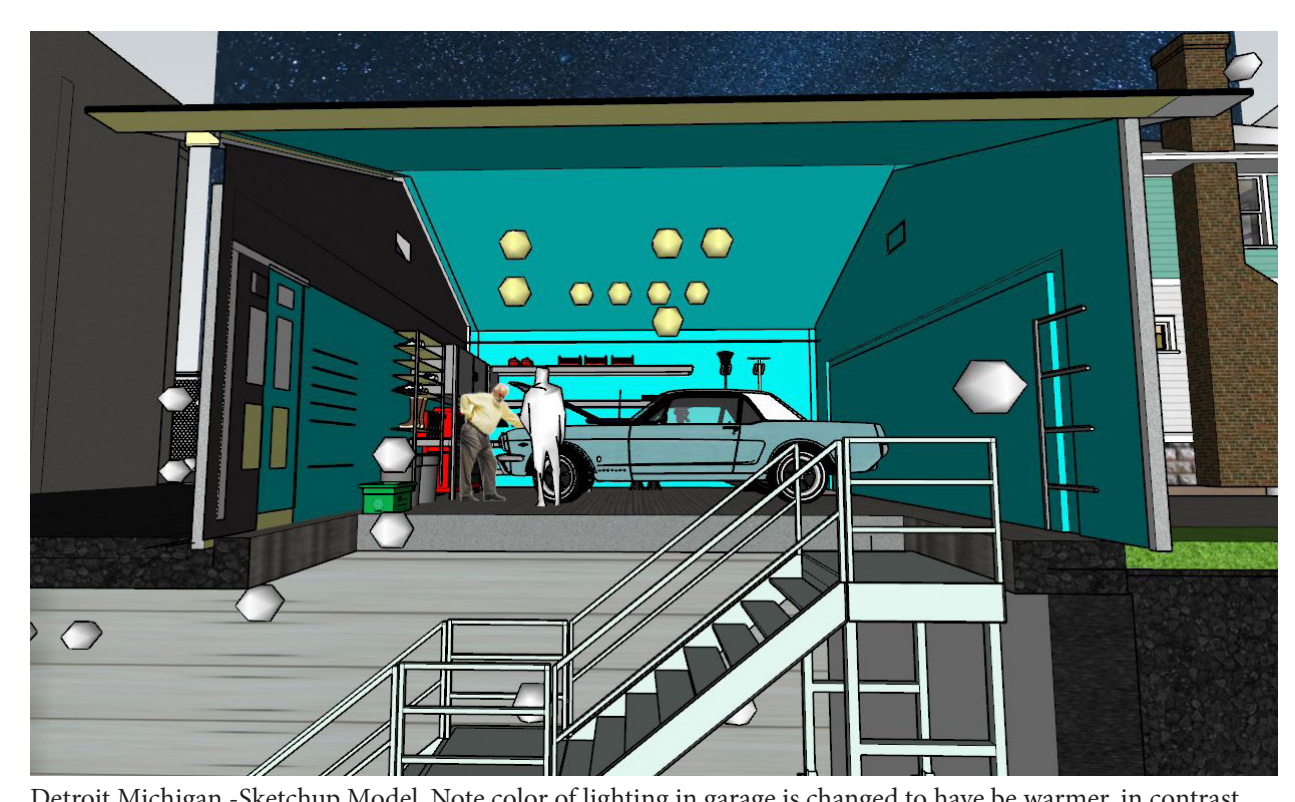

of lighting in garage is ch a png to take on light and give off shadow. The inmate character is an actual enscape model. The starry night
background is simply na ime she Figure 60

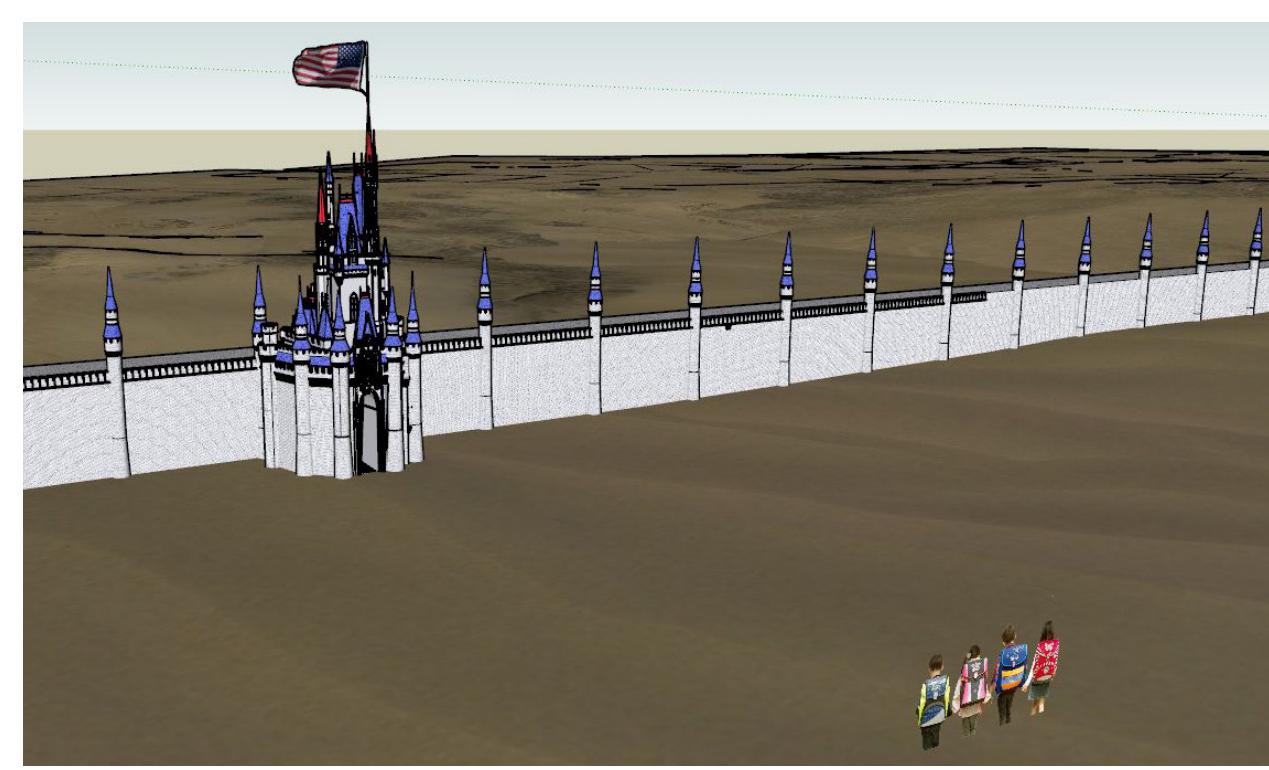

Sanoran Desert - Mexico - Note the false scaling of the children (png. clip art) and the wall. This is done to fake the desired perspective in the final rendering. The mountain background visible in the final rendering is an En-
scape add on. The Castle itself is the Cinderella Castle from Disney World, stretched and modified in sketchup. Figure 61

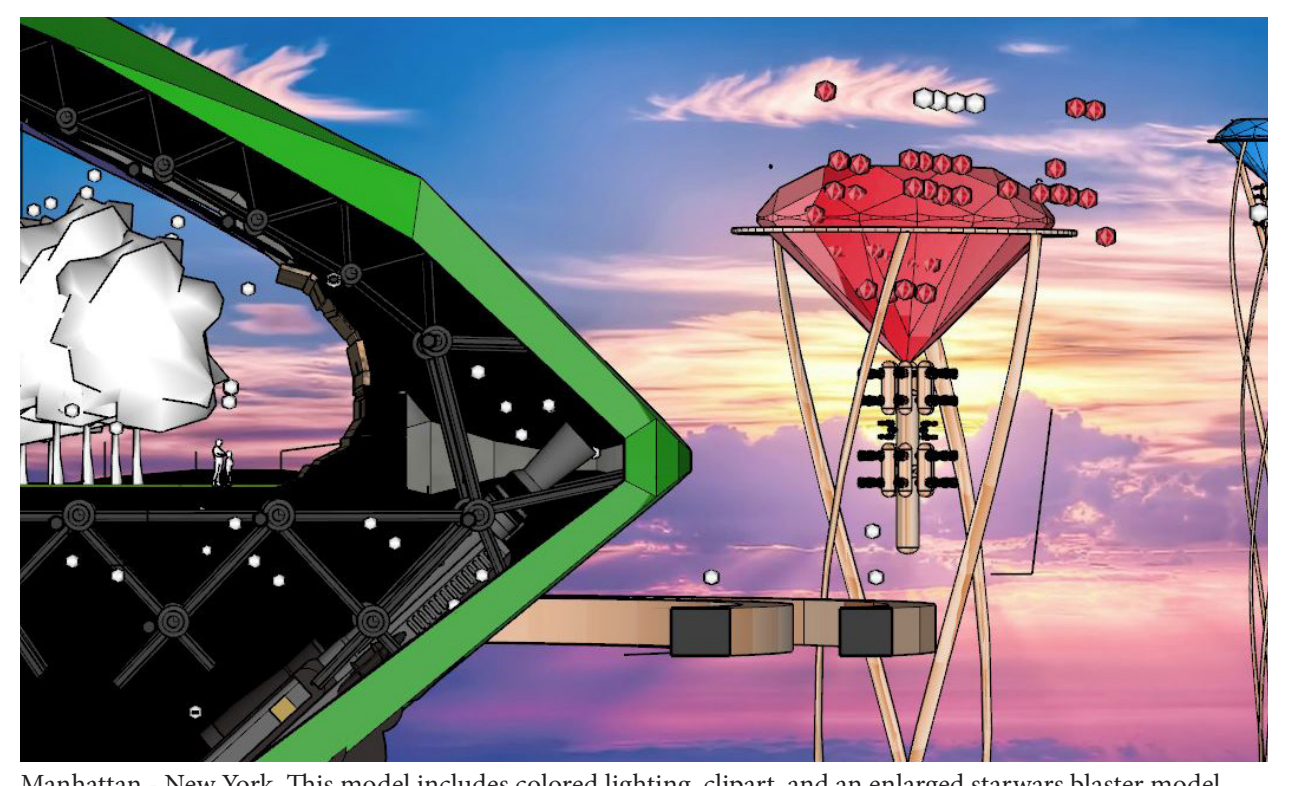
masquerading as a balistic parrachute mechanism. All elements of the structure and defense system are modele in sketchup and surfaced with reflective cladding. Figure 62 


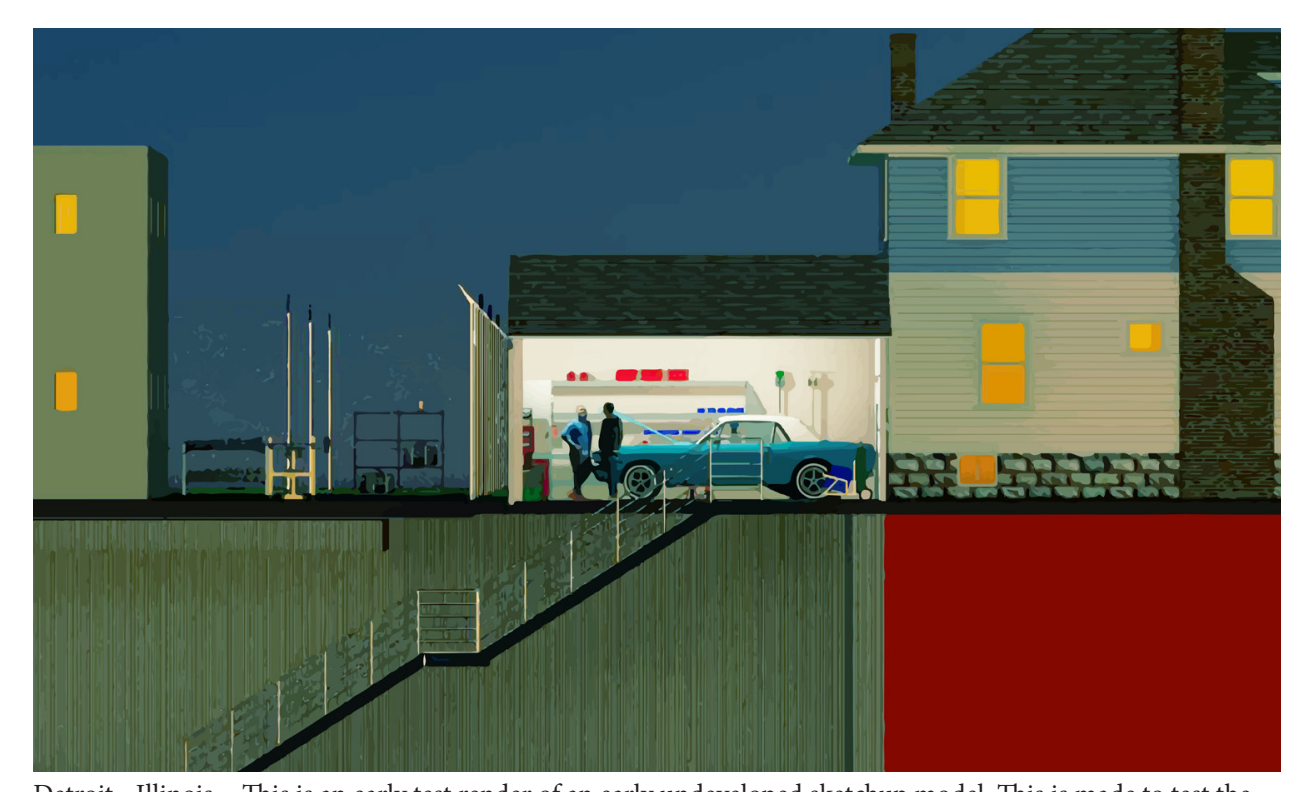
Detroit - Illinois - This is an early test render of an early y Figure 63

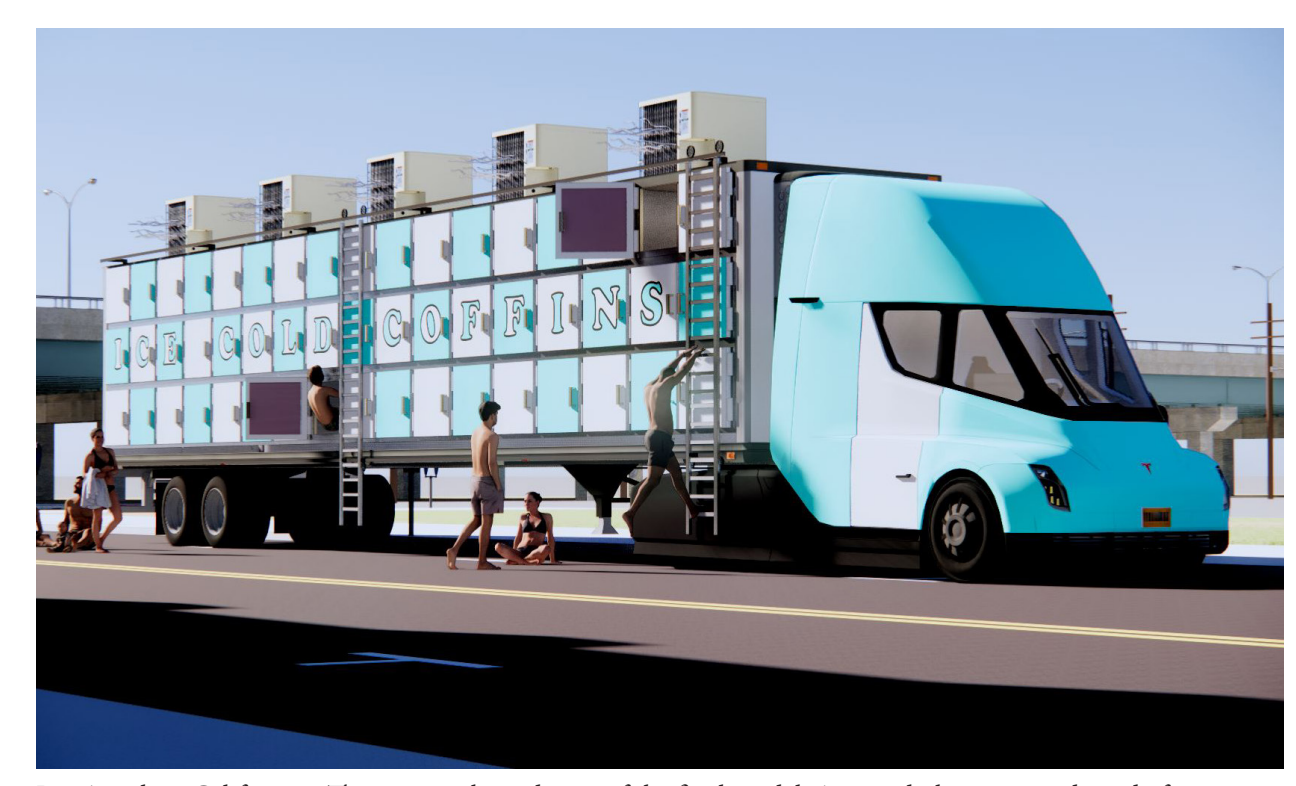

Los Angeles - California - This is a quick rendering of the final model. As noted, the image is devoid of composiFigure 64

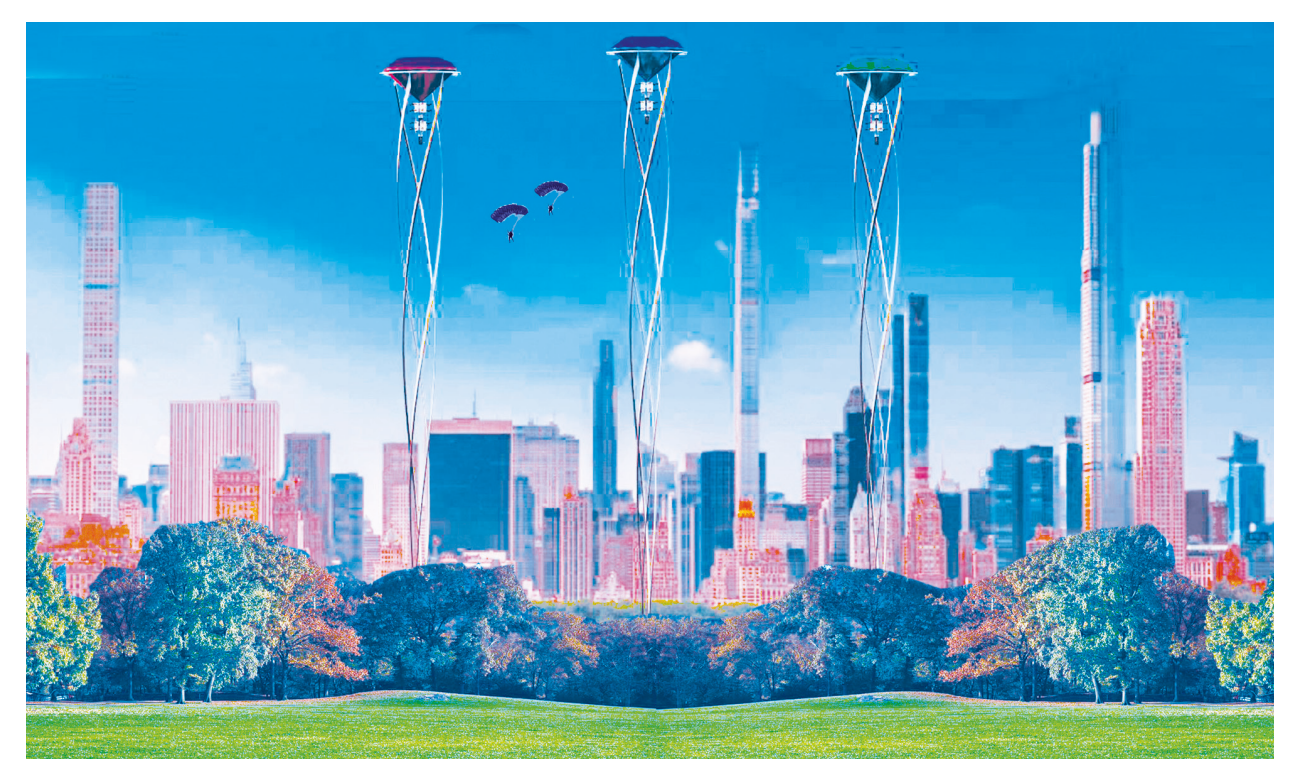

Manhattan - New York. This was a test of an alternate viewpoint for the story rendering. It was not advanced as the characters were not primary in the image, however in hindsight, it is perhaps a more consistent compositionFigure 65

The process of producing the final imagery for the thesis was an iterative exercise of ideation, testing and refinement. The method endeavored to allow ideas to be recorded, tested and modified quickly. I found that Sketchup and Enscape is a powerful tool to represen detailed built environments. Once the software is mastered, good control can be had over composition, lighting, shadow, depth of field, etc. I feel however that it should not be used for initial design. I prefer using more free flowing methods such as pencil or rip and tear modeling for initial layout and testing of the spaces. 


\section{Final Reflections}

\section{IN SEARCH OF A TOPIC}

When searching in mid 2020 for a compelling thesis topic, the social climate in the United States was impossible to ignore. It was in the midst of the Trump re-election campaign, the fallout from the George Floyd murder, the border refugee crisis, and of course, the Covid-19 pandemic. These stories were bombarded into my daily news feed. I couldn't get them out of my head. I decided to develop a thesis that could respond to these critical events through the language of speculative architecture. This thesis would be a therapeutic way of coming to terms with the reality of the world we live in.

\section{IF A TREE FALLS IN THE FOREST...}

I've always had an interest in speculative architecture, however I never particularity engaged with it. To me, most of it was just pretty, carefully line weighted collaged maps destined to dissolve into the vacuum of the academic black hole. If we wish to bring attention to something meaningful and worthy of consideration, I believe we should engage the widest possible demographic with the work. Why not use the method that has worked since the beginning of time, the art of storytelling? This is a cross cultural, uniquely human method to hold an audience's attention and capture their imagination. As such, I decided to respond to the events of 2020 with works of speculative architecture, navigated through a fictional narrative, experienced through the eyes of empathetic character, packaged in an easy to digest, virally disseminate-able visual and written language.

\section{CONSTRUCTIVE PROTEST}

What role would my speculative architecture play in the social commentary? Architecture can and often acts as the role of the oppressor. Several dystopian fictions use it in this manner, however I decided that 2020 had enough negativity already. I wasn’t going to do this. I chose to explore how constructive, non distribute acts of architectural protest could engage both ends of the political spectrum through empathy, understanding, and illustration of our common humanity. I am inspired by the words of late Lebbeus Woods who taught us that Architecture can be a political act. ${ }^{50}$

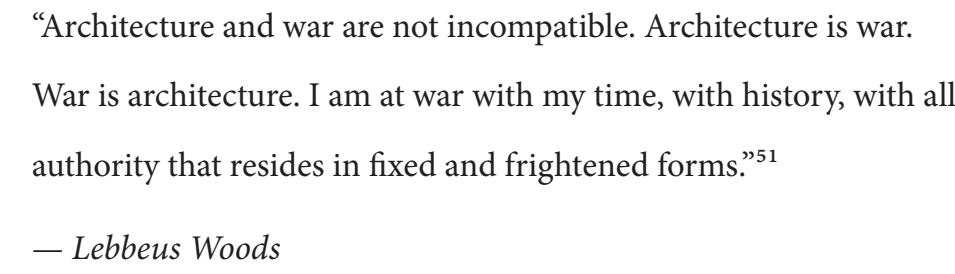

This thesis exploration was not based on a process. It was a thesis in search of a process. The manner in which news and precedent combined with new technology, character, and narrative to form new speculative fictions did not occur in a linear process. Components of the final fictions presented themselves as puzzle pieces, only to be discarded, picked up at a later date and reworked. The spark or inception that caused the joining of image, space, narrative, and character into a coherent speculative fictional narrative is difficult to define As such, this process is not sustainable, as it relies on chance and inspiration which may or may not come. A more comprehensive method to gather relevant headlines, cast empathetic characters, summon the appropriate tech, and pick a backbone and thematic structure for the narrative to build on should be developed. 


\section{LOOKING FOR THE LOOK..}

I wished to develop a cohesive visual language for the fictions. This took time to develop. It culminated into Wes Anderson-esque, character focused planimetric compositions, highlighting somewhat uneventful, non-sensational moments of relatable humanity. I feel that this visual language strikes the right balance between simulated reality to suspend disbelief, and the honest acknowledgment that it is of course, just a tall tale. I believe that the Los Angeles and Detroit fictions were the most successful in this endeavor.

\section{ONLY WORDS...}

The intent of the thesis was to pair visual representations of characters interacting with a fictional built environment with fictional narratives. I struggled with the format of these narratives. They only materialized at the very final stages of the thesis process. I experimented with a screenplay like dialogue, but in the end landed on a first-person journal entry style. The narratives are my attempt of a reductive, Hemmingway-esque style that simply provides the facts and allows the audience to interpret the emotional response of the character, underlaying themes, and embedded social critique. I feel that this worked well, allowing a two way conversation with the viewer, and a direct person to person connection between character and audience.

The Thesis title, STRUCTURE STORIES, is a play on words to the "Story Structure", a principle concern of creative writing, and simply indicates that the thesis is a collection of stories implicitly linked to built structures.

\section{SOME SELF CRITICISM}

I am not entirely satisfied with the visual language and compositional quality of some of the narratives. This is a result of my non-mastery of the software and lack of compositional layout and pre-planning prior to modeling and rendering the spaces. I feel that the thematic and contextual underlayment of the group of narratives should have been more consistent. In general, they lie in a social-political context, and are interwoven with similar themes. All narrative address social ills and a character's reactions to it, however in three cases, the protagonists build the spaces, in one it is unclear who built them, in one the space itself is the antagonist, and in one the space only exists in the minds of the characters. This adds interest however I feel it weakens and muddles the message of the thesis.

\section{FINAL THOUGHTS AND FUTURE}

In general, I am pleased with the result of this thesis journey. By this, I do not refer to the quality of the six final narratives, but the progress in the development of a process to develop future ones. The future of this work has many trajectories. Partnership with those working in parallel disciplines such as film or street graffiti would be a method to connect with a wider audience. If built, these forms of occupied "3D graffiti”, which actually solve a societal injustice for at least the occupants themselves goes a step past simply raising awareness. I hope that this thesis inspires individuals to take control of their own life, refuse to be a victim, and find ways to construct their own destiny.

--TO BE CONTINUED-- 


\section{Bibliography}

1. Lefkowitz, Susan, Tommy. McSweeney's (McSweeney's Quarterly Concern): 2040 AD - Climate Fiction edition, no. 58 (New York, McSweeney's Quarterly Concern, 2019)

2. Russell, Khrisha. “Abaco Tragedy - Did 65 Perish? 18 Survivors, 30 Bodies Recovered, But Still Missing." The Tribune, February 7th 2019. http://www.tribune242.com/news/2019/feb/07/aba co-tragedy-did-65-perish-18-survivors-30-bodies/

3. "Hurricane Dorian: 75,000 may need urgent aid on Bahamas" Aljazeera, September 6th 2019. https://www.aljazeera.com/news/2019/9/6/hurricane-dorian-75000-may-need-urgent-aid-on-ba hamas

4. De Vignemont, Frederique. When do we empathize? Novartis Foundation symposium 278, (Octo ber 2006) pp.180-195. https://doi.org/10.1002/9780470030585.ch13

5. Castano, Emanuelle. Art films foster theory of mind. Humanities and Social Science Communica tions 8, 119 (2021). https://doi.org/10.1057/s41599-021-00793-y

6. Miller, Greg. "How Movies Trick Your Brain Into Empathizing With Characters" Wired, September 2nd 2014. https://www.wired.com/2014/09/cinema-science-empathizing-with-characters/
7. Decety J, Bartal IB, Uzefovsky F, Knafo-Noam A. Empathy as a driver of prosocial behaviour highly conserved neurobehavioural mechanisms across species. Philosophical transactions of the Royal Society of London. Series B, Biological sciences. 2016 Jan 19;371(1686):20150077. doi 10.1098/rstb. 2015.0077. PMID: 26644596; PMCID: PMC4685523.

8. Decety J, Bartal IB, Uzefovsky F, Knafo-Noam A. Empathy as a driver of prosocial behaviour: highly conserved neurobehavioural mechanisms across species. Philosophical transactions of the Royal Society of London. Series B, Biological sciences. 2016 Jan 19;371(1686):20150077. doi: 10.1098/rstb.2015.0077. PMID: 26644596; PMCID: PMC4685523.

9. Kaufman, Will. The Civil War in American culture. Edinburgh: Edinburgh University Press, 2006

10. Charles Edward Stowe. Harriet Beecher Stowe: The Story of Her Life (1911) p. 203

11. O'Hagan, Sean. “America's first king of the road," The Guardian. May 20, 2010. https://www. theguardian.com/books/2007/aug/05/fiction.jackkerouac

12. Niccum, Jon "Fallout from 'The Day After'." LJ World, November 19th 2003. http://www.lawrence. com/news/2003/nov/19/fallout_from/

13. Nobis, Nathan. The "Babe" vegetarians: bioethics, animal minds and moral methodology. In S.Shapshay (Ed.), Bioethics at the movies. Baltimore: Johns Hopkins University Press. (pp. 56-73).

14. Miller, Greg. "Pakistan passes legislation against 'honor killings" CNN October 8th 2016. https://www.cnn.com/2016/10/06/asia/pakistan-anti-honor-killing-law/index.html/

15. Ghosn, Rania, Jazairy, El Hadi. Geostories: another architecture for the environment - Design Earth (London: Actar, 2018) 
16. Woods, Lebbeus. "WAR AND ARCHITECTURE: Three Principles" LEBBEUS WOODS. December 152011

https://lebbeuswoods.wordpress.com/2011/12/15/war-and-architecture-three-principles/

17. Anderson, Darran “The Prophetic Side of Archigram” Bloomberg November 15th 2017. https:// www.bloomberg.com/news/articles/2017-11-15/archigram-and-the-modern-city

18. Anderson, Darran "The Prophetic Side of Archigram" Bloomberg November 15th 2017. https:// www.bloomberg.com/news/articles/2017-11-15/archigram-and-the-modern-city

19. Chapman, Michael; Ostwald, Michael J. The underbelly of an architect: discursive practices in the architecture of Douglas Darden (Society of Architectural Historians, Australia and New Zealand)

20. Ghosn, Rania, Jazairy, El Hadi. Geostories: another architecture for the environment - Design Earth (London: Actar, 2018)

21. Giardino, Neil "After a year of protests, Portland residents have waning patience for antifa" ABC News May 5th 2021 https://abcnews.go.com/US/year-protests-portland-residents-waning-pa tience-antifa/story?id=77511470

22. Chak, Tings. Undocumented: The Architecture of Migrant Detention (Montreal: The Architecture Observer, 2014)

23. Draaisma, Muriel. "Doctors say Ontario children suffering from 'social malnutrition' during COVID-19 pandemic" CBC April 14th 2020 https://www.cbc.ca/news/canada/toronto/social-mal nutrition-ontario-medical-association-doctors-children-teens
24. Wallace, Lewis "Lebbeus Woods: The Architect Who Dared to Ask "What If?" Wired February 15th 2013 https://www.wired.com/2013/02/lebbeus-woods-conceptual-architect/

25. Hass, Jacob, Gascon, Charles S. "The Impact of COVID-19 on the Residential Real Estate Market" Federal Reserve Bank of St Louis October 6th, 2020 https://www.stlouisfed.org/publications/re gional-economist/fourth-quarter-2020/impact-covid-residential-real-estate-market

26. Nagesh, Ashitha "This police-free protest zone was dismantled - but was it the end?" BBC July 12th2020 https://www.bbc. com/news/world-us-canada-53218448

27. Scigliano, Eric "Don’t Listen to Fox. Here’s What's Really Going On in Seattle’s Protest Zone" Getaka News June 16th 2020 https://getaka.co.in/usa-news/dont-listen-to-fox-heres-whats-reallygoing-on-in-seattles-protest-zone/

Bang, Hyun “The stubborn 'nail houses' protesting China’s rapid urbanization" City Monitor March 23rd 2017 https://citymonitor.ai/politics/stubborn-nail-houses-protesting-china-s-rapid-urbanisa tion-2901

29. Gross, Terry "A 'Forgotten History' Of How The U.S. Government Segregated America " NPR May 3rd 2017 https://www.npr.org/2017/05/03/526655831/a-forgotten-history-of-how-the-u-s-govern ment-segregated-america

30. Watt, Nick "Racist language is still woven into home deeds across America. Erasing it isn't easy and some don't want to" CNN February 15th 2015 https://www.cnn.com/2020/02/15/us/rac ist-deeds-covenants/index.html

31. Gotsch, Kara "Capitalizing on Mass Incarceration: U.S. Growth in Private Prisons" 
The Sentencing Project August 2nd 2018 https://www.sentencingproject.org/publications/capitaliz ing-on-mass-incarceration-u-s-growth-in-private-prisons/

Sawyer, Wendy "Visualizing the racial disparities in mass incarceration" Prison Policy Initiative July 27th 2020 https://www.prisonpolicy.org/blog/2020/07/27/disparities/

33. Seegert, Liz 'I'm very lonely and depressed'- many nursing home residents say they feel like they are in prison" MarketWatch October 12th 2020 https://www.marketwatch.com/story/im-very-lone ly-and-depressedmany-nursing-home-residents-say-they-feel-like-they-are-in-prison-2020-10-12

34. Saporito, Jeff "How Does “The Shawshank Redemption" Illustrate The Power Of Hope?" The Take https://the-take.com/read/how-does-the-shawshank-redemptiona-illustrate-the-power-of-hope

Chapman, Michael; Ostwald, Michael J. The underbelly of an architect: discursive practices in the architecture of Douglas Darden (Society of Architectural Historians, Australia and New Zealand)

MacLeod, Gordon, and Kevin Ward. "Spaces of Utopia and Dystopia: Landscaping the Contempo rary City." Geografiska Annaler. Series B, Human Geography 84, no. 3/4 (2002): 153-70. Accessed May 31, 2021. http://www.jstor.org/stable/3554313.

37. Hesson, Ted. "Explainer: Why more migrant children are arriving at the U.S.-Mexico border" Reuters March 18th 2021 https://www.reuters.com/article/us-usa-immigration-children-explaine r-idUSKBN2BA11B

38. Long, Colleng. "No clear plan on how to reunite thousands of children taken from parents: Trump official" Global News June 20h 2018 https://globalnews.ca/news/4285109/donald-trump-immigra tion-reunite-parents-children-u-s-border/
Chak, Tings. Undocumented: The Architecture of Migrant Detention (Montreal: The Architecture Observer, 2014)

40. Schoolov, Katie. "Why some tech companies and billionaires are leaving California" CNBC, January 23rd 2021 https://www.cnbc.com/2021/01/23/why-companies-are-fleeing-california.htm

41. Bahney, Anna. “This bunk bed is $\$ 1,200$ a month, privacy not included” CNN, July 5th 2019 https://www.cnn.com/2019/07/05/success/podshare-co-living/index.htm

42. Barboza, Tony. "As second heat wave sears California, experts say health impacts will worsen with climate change" LA Times, September 5th 2020 https://www.latimes.com/california/sto ry/2020-09-05/heat-health-risks

3. https://en.wikipedia.org/wiki/Reaganomic

44. Brumfield Hessen, Emily. "America’s Conspiratorial Delusions Weren’t Born Under Trump" Foreign Policy, February 26th 2021 https://foreignpolicy.com/2021/02/26/qanon-conspira cy-trump-right-wing-media/

45. Cathey, Libby. "Legacy of lies -- how Trump weaponized mistruths during his presidency" ABC News, January 20th 2021 https://abcnews.go.com/Politics/legacy-lies-trump-weaponized-mis truths-presidency/story?id=75335019

46. Raymond, Adam. "Does Trump Ever Lie? White House Press Secretary Says 'No' The Intelligencer August 28th 2019 https://nymag.com/intelligencer/2019/08/trumps-new-press-secretary-says-henever-lies.html 
47. Eordohg, Fruzsina “The 'Free Melania' Meme Was Never About Pity” Forbes, January 26 th 2017 https://www.forbes.com/sites/fruzsinaeordogh/2017/01/26/the-free-melania-meme-was-neverabout-pity/?sh=222541356046

48. https://en.wikipedia.org/wiki/The_Great_Gatsby

49. https://en.wikipedia.org/wiki/Graphene

50. Woods, Lebbeus. "WHAT IS ARCHITECTURE” LEBBEUS WOODS. November 13 2007. https:// Lebbeuswoods.wordpress.com/2007/11/13/what-is-architecture/

51. Woods, Lebbeus. “WAR AND ARCHITECTURE” LEBBEUS WOODS. December 2nd, 2011. https://lebbeuswoods.wordpress.com/2011/12/02/war-and-architecture-the-sarajevo-window/ 